\title{
OroAntral Communications and OroAntral Fistula
}

\author{
Suvy Manuel
}

\begin{abstract}
Routine exodontia is a common procedure performed by the general dental practitioner and the oral surgeon alike. Most of the maxillary premolar/molar extractions heal uneventfully but some may cause inadvertent opening into the maxillary sinus, manifesting as immediate oro antral communications $(O A C)$ or delayed oro antral fistulae. The common reasons being difficulty encountered in the extractions intra operatively due to myriad reasons or the OAC may be due to a pre existing pathology in the peri apical region or within the sinus lining. Whatever the reason be, its paramount that the surgeon identifies the problem and approach it in a sequential manner to avoid long term consequences and to attain a perfect closure. The timing of the closure is crucial which is dependent upon the sinus health and the socket condition. This may be complicated by a missing root tip which is lying in the sinus. This chapter aims to walk the reader through these events in a logical fashion, so that they can take appropriate decisions and use the correct surgical technique which will ensure a successful closure of the defect.
\end{abstract}

\subsection{Introduction}

Maxillary sinus is an anatomical area, which is intimately associated with the field of oral and maxillofacial surgery. Many of the procedures done violate the integrity of the maxillary sinus, as in orthognathic surgeries, or when the sinus is involved per se as part of midface trauma or in odontogenic pathologies that infringe upon the sinus.

The relevance of the sinus in day-to-day minor dentoalveolar surgical procedures is that the sinus floor is in very

Electronic Supplementary Material The online version of this chapter (https://doi.org/10.1007/978-981-15-1346-6_24) contains supplementary material, which is available to authorized users.

S. Manuel $(\bowtie)$

Department of Oral and Maxillofacial Surgery, Ananthapuri

Hospitals and Research Institute, Trivandrum, Kerala, India

Kerala Institute of Medical Sciences, Trivandrum, Kerala, India close approximation with the roots of the maxillary posterior teeth, especially the molars [1].

Eberhardt, in 1992, did a CT study to evaluate the distance between maxillary sinus floor and the apices of the maxillary pre-molar/molar teeth. The buccal first premolar showed the largest value of $6.18 \mathrm{~mm}$ (SD $1.60 \mathrm{~mm})$. It is quite disturbing to know that the mesiobuccal root of maxillary second molar is only $0.83 \mathrm{~mm}$ (SD $0.49 \mathrm{~mm}$ ) away from the maxillary sinus floor, as per this study results. Readers are advised to refer the table in reference [1] to have a better picture of this relevant CT study.

This intimate relation with the root of maxillary molars causes many a time inadvertent communication between the sinus and oral cavity causing acute OroAntral communication (OAC). If the OAC is unrecognized or not dealt with primarily, either it may undergo spontaneous healing if the circumstances are favourable or it may progress into a fullfledged OroAntral fistula (OAF), which will need secondary intervention for closure.

This section of the book deals with OAC and OAF caused during exodontia and minor dentoalveolar surgical procedures, cyst enucleation and small-sized tumour excision.

Communications caused due to excision of moderate to large pathologies, post-oncosurgery defects, major maxillofacial trauma, gunshot/missile injuries, osteoradionecrosis and developmental and congenital deformities usually may require locoregional/free flap transfers and/or prosthetic rehabilitations. Such communications are dealt with elsewhere in this book.

This section is limited to closure of OAF caused after exodontia; however, many surgical techniques used for OAF closure do overlap with surgical closure techniques of oronasal and palatal fistulas. Those techniques are dealt with in relevant sections of the book.

This chapter also deals with managing and retrieving root/root tips, which are inadvertently displaced into the sinus (Root in sinus).

Most of the surgical procedures aimed at correction of $\mathrm{OAC} / \mathrm{OAF}$ are doomed to fail if the underlying sinus is not 
healthy before the anticipated closure. The "Antral regime procedures" are aimed at ensuring a disease-free sinus before anticipated elective closure of a post-extraction OAF. When patients are referred to oral surgeons for treatment of OAF, depending upon the duration of complaint, the sinus may be in various stages of the disease. It is difficult to ascertain whether the sinus was diseased primarily at the time of exodontia, accentuating the chance of an OAF formation or whether the sinus had been secondarily infected following the formation of OAF due to direct communication with the oral cavity. Another possibility is that the sinus lining would have been secondarily involved by a periapical pathology and removal of the involved tooth was conducive to the formation of the OAC.

The role of an otorhinolaryngologist cannot be understated, and at times, the closure has to be attempted after consulting with them regarding the sinus health. Their presence may be required during the closure for allied procedures in the sinus like FESS (Functional Endoscopic Sinus Surgery).

\subsection{Aetiology of OAC}

The common causes for OAC during dentoalveolar procedures are

1. Aberrant anatomy causing the sinus floor to dip down between the roots of premolars and molars/decreased thickness of sinus floor.

2. Unusually long roots, which lie in close proximity to the sinus floor/Schneiderian membrane.

3. Dense alveolar bone causing difficult extractions.

4. Removal of root canal-treated maxillary molars is usually difficult due to the brittle nature of the tooth.

Attempted removal of brittle root tip fractures in such teeth shows an increased chance of getting OAC.

5. Improper use of dental elevators when attempting to remove root tip can cause undue vertical forces, whichmay push the roots into the sinus (Fig. 24.1).

6. Progressive pneumatization of the sinus as age advances, especially around lone standing molars (Fig. 24.2).

7. Progressive pneumatization is also a cause for OAC during removal of maxillary third molars especially when associated with tuberosity fractures.

8. Teeth, which have periapical pathologies, cause bone loss/erosion at the sinus floor and are at a higher chance of causing OAC after extractions. It is imperative that such cases are identified pre-operatively, adequate radiographic examinations are done, the patients are pre-warned and necessary measures are to be taken to close the OAC, if they occur during the procedure (Fig. 24.3a, b and c).

9. Occasionally, odontogenic infections/abscess may spread to the sinus, which may manifest "Fluid levels" in the sinus on paranasal sinus X-rays. Extraction of such teeth involves a greater chance of having OAC.

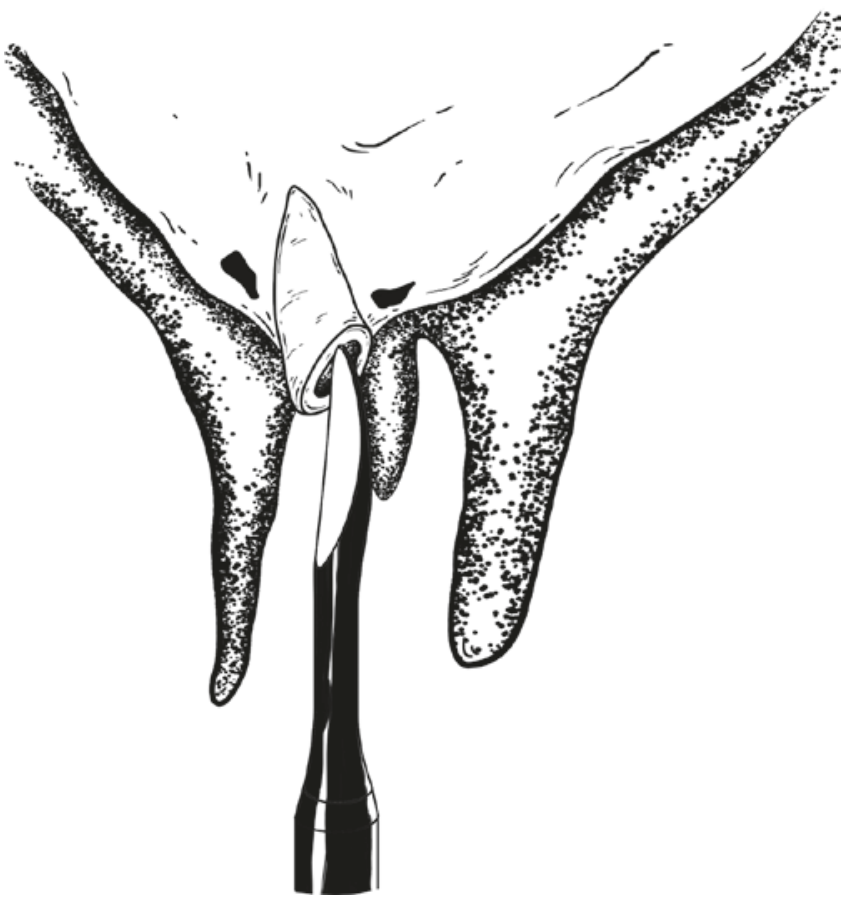

CAssociation of Oral and Maxillofacial Surgeons of India

Fig. 24.1 Improper use of dental elevators causing pushing of root tip into maxillary sinus

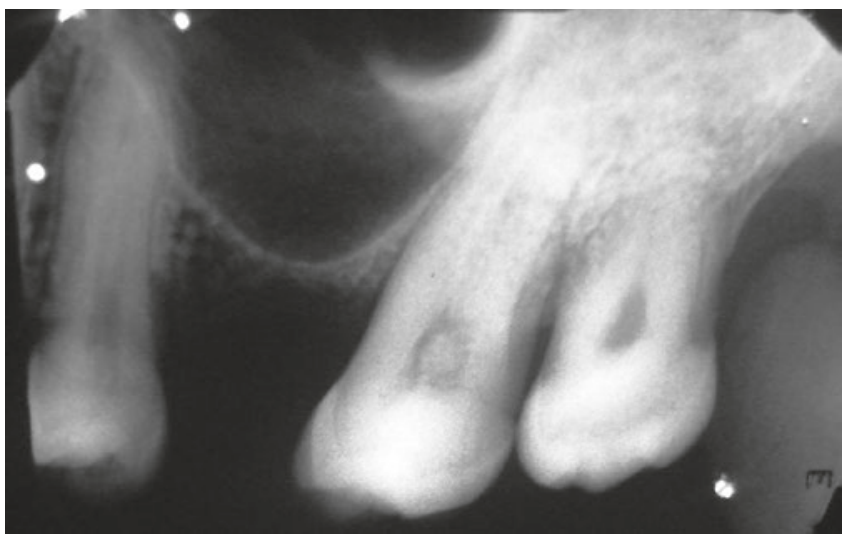

CAssociation of Oral and Maxillofacial Surgeons of India

Fig. 24.2 Sinus dipping down in a long-standing edentulous area of upper left first molar (IOPA)

10. Lack of adherence to basic principles of dentoalveolar surgery or overzealous/aggressive attempts to remove or retrieve fractured root tips of maxillary posterior teeth may cause OAC. It is the judgement of the concerned clinician whether to attempt removal of a fractured root tip; if the clinician can remove the root tip via the socket through closed intra-alveolar technique well and good, if not the clinician should be able to remove the tip via transalveolar technique based on sound dentoalveolar surgical principles and should be able to close the OAC if it occurs. If the clinician feels that he is not able to perform the above-mentioned procedure, it may be wise 
Fig. 24.3 (a) IOPA of a molar showing periapical lesion, (b) Extracted molar with the lesion attached to the root tip, (c) Diagrammatic representation of periapical lesion close to sinus floor
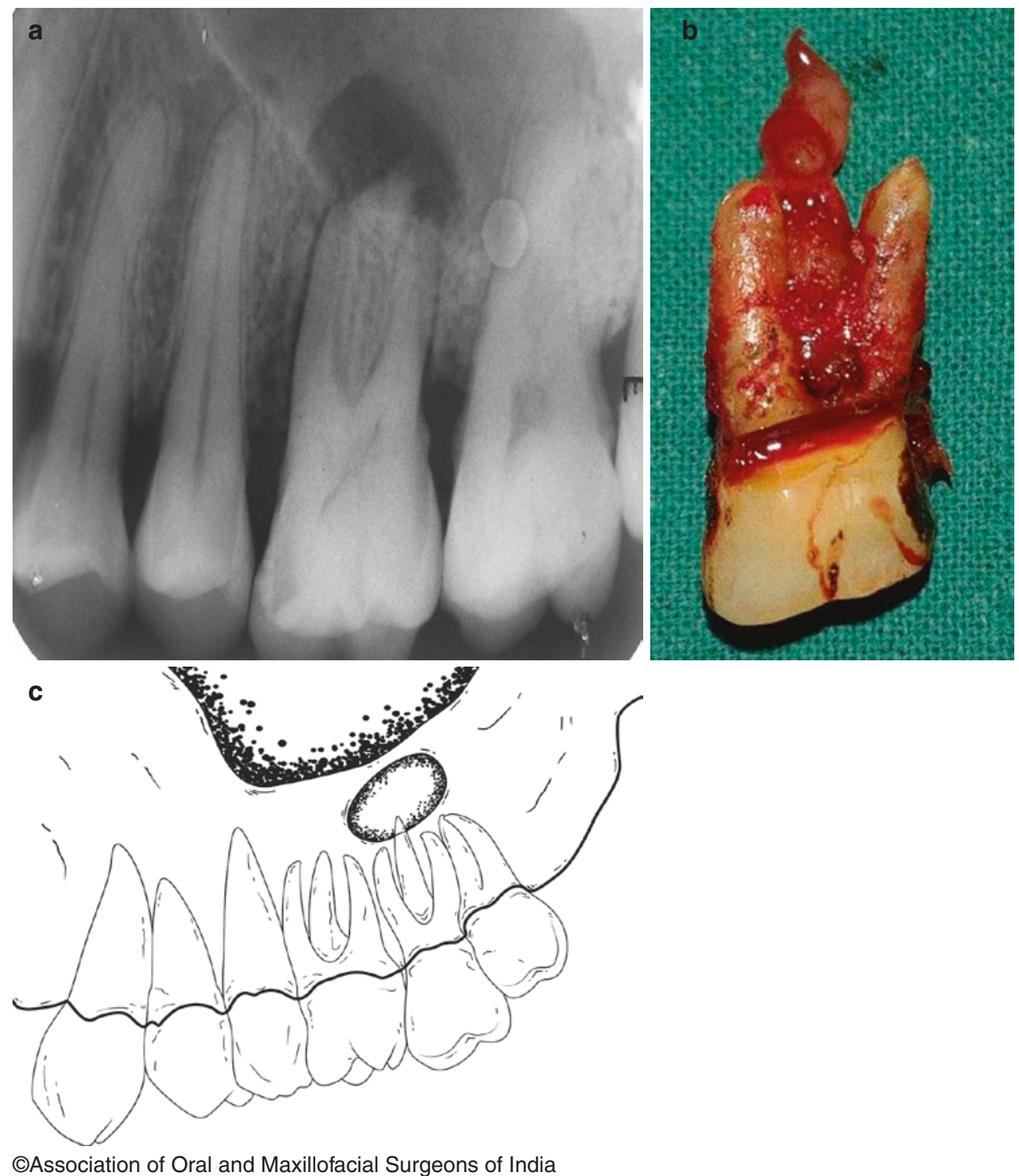

(C)Association of Oral and Maxillofacial Surgeons of India not to vigorously attempt to remove the root tip. Either he should get expert help or it would be judicious to leave the root tip behind and attempt removal later if required when expert help is available (Fig. 24.4).

11. Teeth, which have aberrant root anatomies, dilacerations, hypercementosis and ankylosis, are all at risk of developing OAC.

\subsection{Clinical Features of OAC}

The basic rule to be followed when we suspect an OAC is never to enlarge or aggravate the existing communication. Most of the time OAC goes unrecognized, and it may heal spontaneously if it is less than $3-5 \mathrm{~mm}$ in diameter [2]. If a bigger $\mathrm{OAC}$ is not recognized and adequate measures are not taken for closure, it may progress to OAF. Unless it is an evident OAC, confirmatory tests are not done in order to prevent enlarging the OAC. Literature also says that sinusitis will ensue if the OAC is not closed within 24-48 h.

1. Bubbling of mucous or blood may be seen at the socket opening when the patient exerts pressure via a closed nostril (Valsalva manoeuvre).

2. Patient may feel oronasal regurgitation or leaking of oral fluids via nose if they hold water in mouth.

3. There may be unilateral epistaxis on the affected side.

4. Close examination of the socket apex under direct light vision may show the sinus lining or opening into the sinus.

5. There may be changes in the resonance of the voice.

6. An OAC should be suspected if a piece of antral floor is attached to the root end after extraction (Fig. 24.5). 


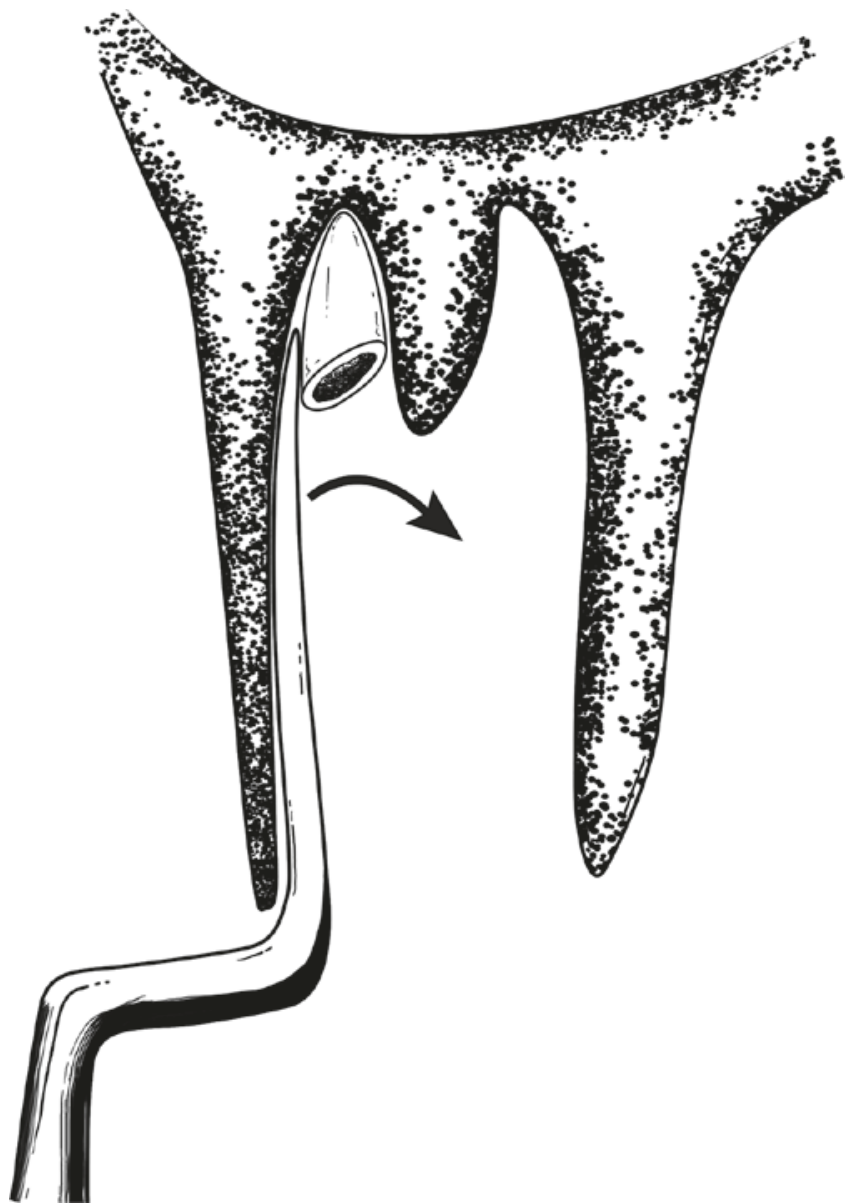

CAssociation of Oral and Maxillofacial Surgeons of India

Fig. 24.4 Diagram showing the importance of slow, careful and fine movements to remove root tips with straight probes, fine mosquito forceps or apical fragment ejectors

\subsubsection{Radiological Features of OAC}

There may not be radiological evidence of a small OAC on a routine IOPA, unless there is sizeable loss of antral floor or breach in antral floor, which will manifest as a direct communication between the sinus and socket. It is not advisable to insert a probe or radiopaque marker into the socket and take an $\mathrm{x}$-ray as it may enlarge the OAC.

\subsubsection{Management of OAC}

The OAC may be managed in the following step wise approach:

1. If you suspect an OAC, it is prudent to inform the patient about the anticipated treatment plan and the sequel.

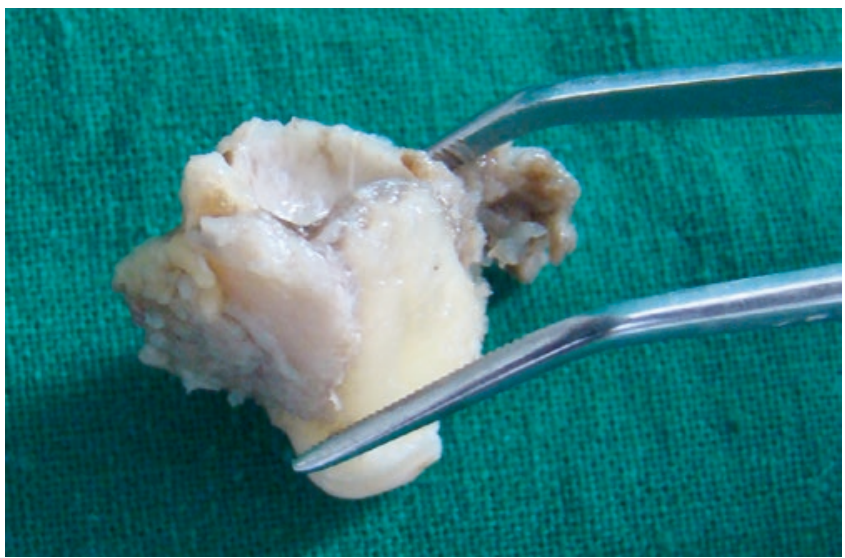

CAssociation of Oral and Maxillofacial Surgeons of India

Fig. 24.5 Note the sinus floor attached to the roots of an upper third molar after extraction, with associated tuberosity fracture. It is a definite case of $\mathrm{OAC}$, which warrants primary closure if conditions are favourable

Patient has to be aware of the condition as postoperative compliance form of the patient is of paramount importance in order to prevent any dehiscence or clot break down at the OAC closure site. (See antral regime section.)

2. Openings less than $3-5 \mathrm{~mm}$ in size may be left without any intervention hoping for spontaneous healing, or a primary closure may be attempted depending upon individual case scenarios. If left for spontaneous healing, patients are specifically instructed to avoid any manoeuvres, which may increase the intra-sinus pressure.

A routine suturing across the socket in maxillary premolar/molar extraction sites may not suffice in suspected cases of OAC, as the buccal and palatal gingivae may not approximate primarily and healing may be secondary in nature. Suturing in such cases just plays a role in supporting the clot. If aiming at primary closure to treat $\mathrm{OAC}$, the buccal and palatal gingivae may be approximated by the following additional measures:

(a) Reduce the height of the buccal/palatal alveolar bone in order for the sutures to approximate.

(b) As it is the palatal mucoperiosteum that is more adherent, a semilunar relaxing incision may be placed about $5 \mathrm{~mm}$ away from the palatal gingival edge and the flap is advanced buccally to meet the buccal gingivae (Fig. 24.6). 


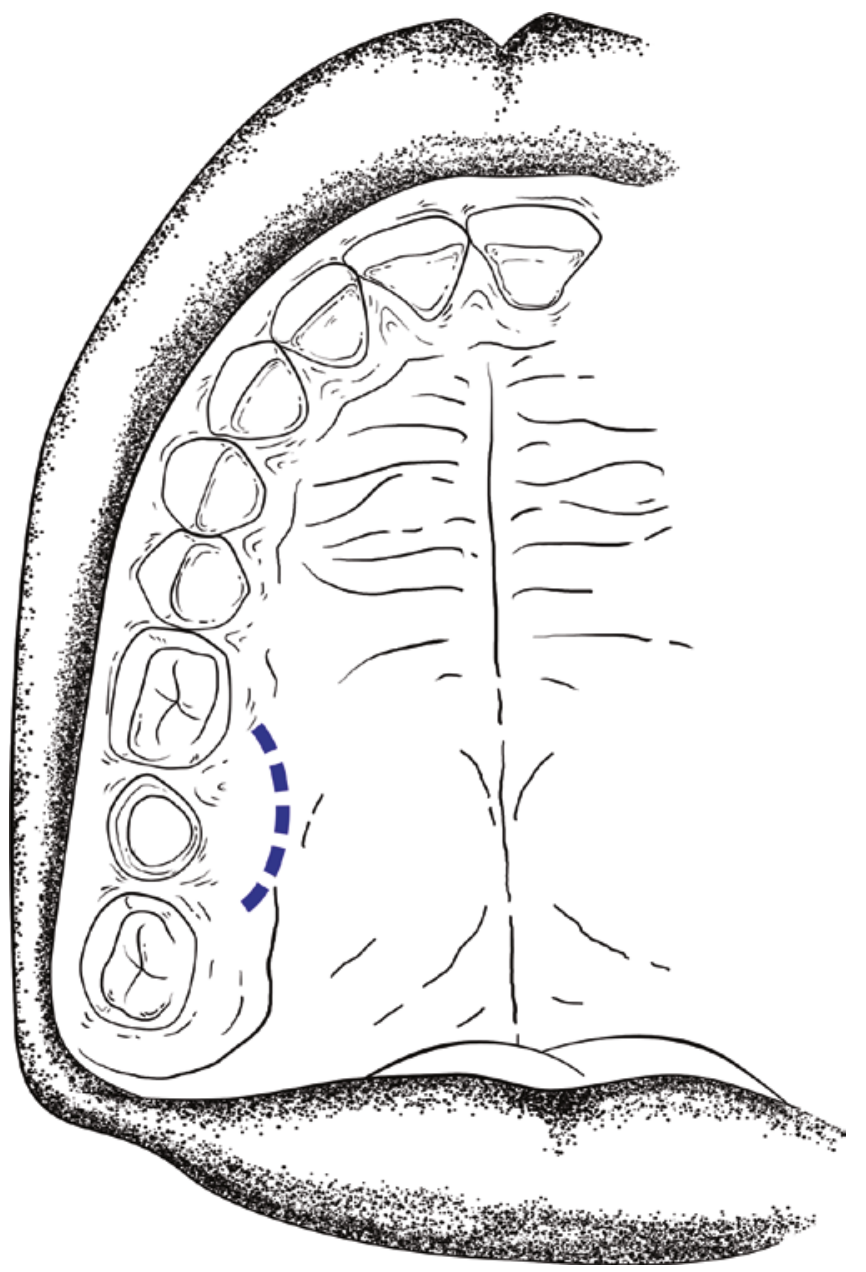

CAssociation of Oral and Maxillofacial Surgeons of India

Fig. 24.6 Depicts releasing incision in the palate, to advance the flap in order to achieve primary closure of the socket

Beyond these two steps, any attempt at closing the OAC would mean that the surgeon is using techniques that are common with established techniques of closing an OAF. If primary closure is not obtained by (a) or (b), the next logical step would be to raise a buccal full thickness three-sided (trapezoidal/rectangular/4 cornered) flap and advancing it to the palatal side. At this stage, if adequate relaxation is not present for the flap, the mucoperiosteum may have to be scored and the details of this are given in OAF surgical closure section of this chapter.

If the sinus is healthy, the best chance of closing an OAC is at the time of occurrence and the surgeon may use any of the techniques in his armamentarium, and these decisions are taken on a case-by-case basis.

\section{Clinical Scenario 1}

A simple clinical scenario is given here as food for thought for the young readers (Fig. 24.7).

I believe that there may be different opinions, with few possible ones being

1. Extract the tooth and allow the lesion to regress/ observe periodically.

2. Extract the tooth and curette/attempt enucleation via socket.

3. Extract the tooth via transalveolar technique and enucleate the lesion.

4. Further investigations/imaging before attempting extraction.

5. Assess the sinus condition before performing any extraction.

6. Be aware of the possibility of an OAC after extraction and be prepared for the possible technique of closure.

This case was included just to show how perplexing a routine clinical situation could be and to stress on the importance of a solid pre-operative plan before attempting such cases.

\subsection{OroAntral Fistula}

Intrusion into the maxillary sinus and establishment of direct communication with the oral cavity are referred to as an oroantral fistula (Fig. 24.8a and b). An oroantral fistula is a pathological condition in which the oral and antral cavities have a permanent communication by means of a fibrous connective tissue fistula coated by epithelium. Once an unrecognized OAC does not heal or there is failure of attempted closure, the condition progresses to an OAF, which means that the epithelization of the communicating tract has occurred. Usually, such cases get referred to the oral surgeon from the general dental practice within 2-3 weeks of the occurrence, when patient notices oronasal regurgitation.

\subsubsection{Aetiology of OAF}

The causes for OAF are similar to those of OAC mentioned earlier. Apart from this, if the sinus has pre-existing sinusitis/antral pathology/fungal infections/fungal balls, the 
Fig. 24.7 This is the OPG of a 25-year-old man who reported for routine extraction of root stump of upper left first molar tooth. OPG shows an incidental finding of a periapical lesion (which is probably a periapical cyst that appears to be very close to the sinus floor or probably pushing the sinus lining up). How would you manage this case?

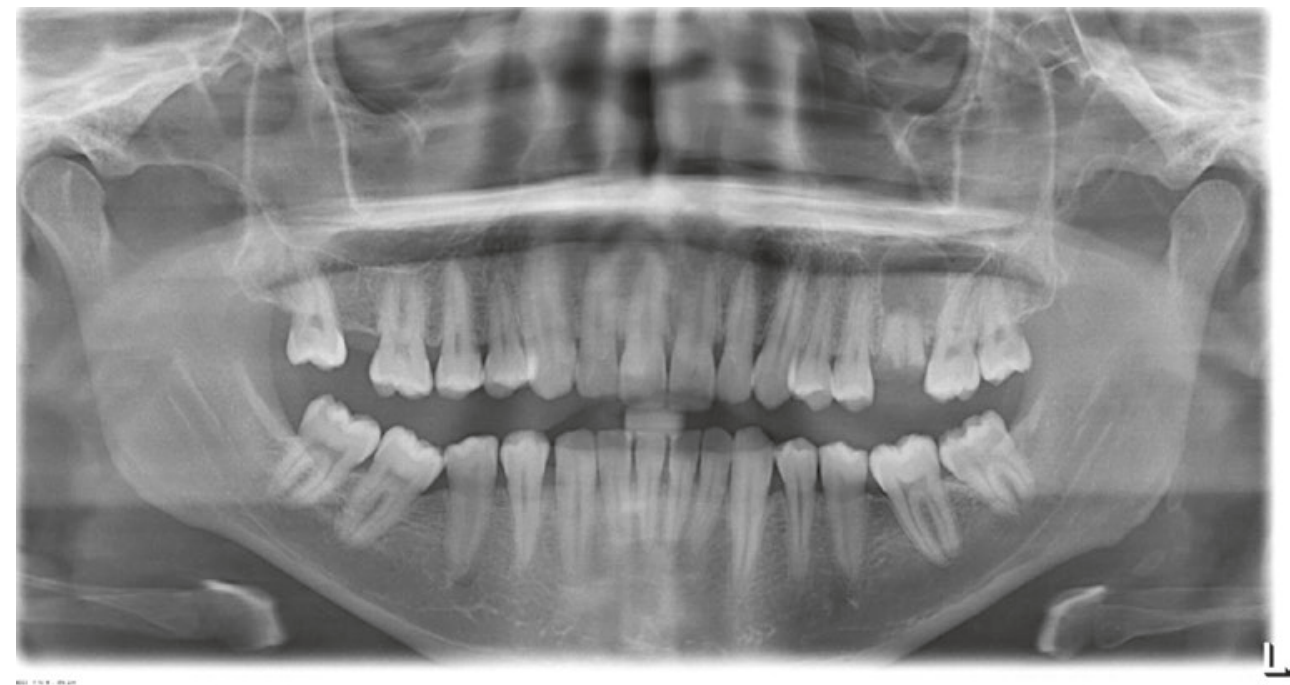

(C)Association of Oral and Maxillofacial Surgeons of India
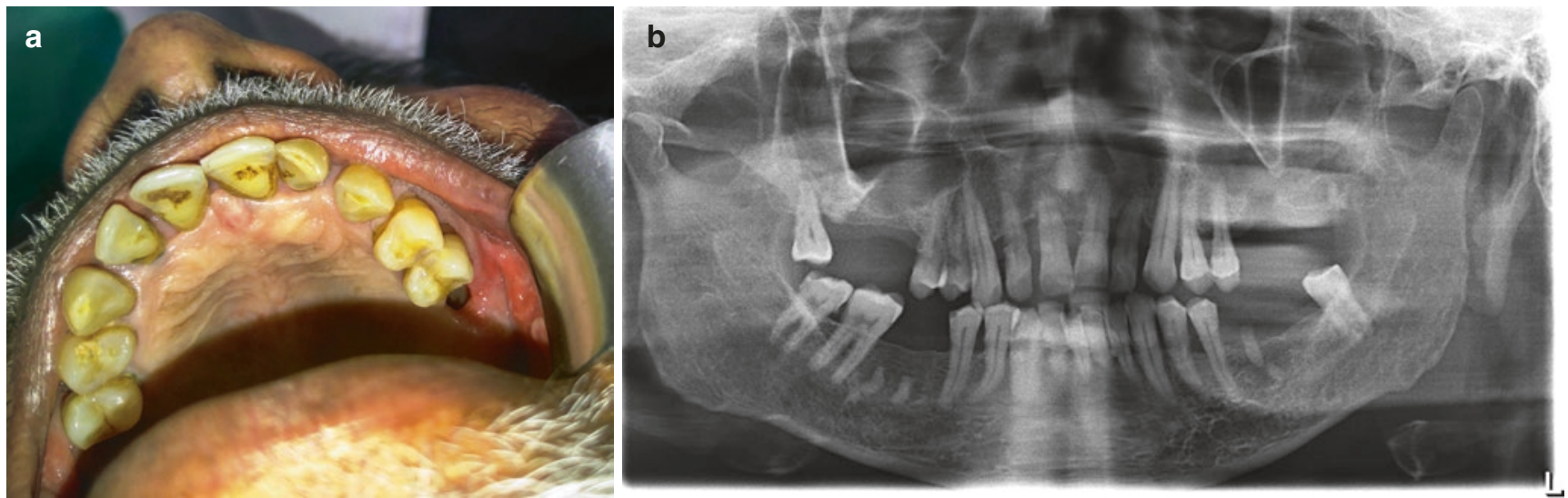

CAssociation of Oral and Maxillofacial Surgeons of India

Fig. 24.8 (a) Note the OAF on upper left first molar extraction site. The socket edges are well-healed, epithelized and rounded off. (b) OPG of the above case showing a defect in the alveolar ridge in the 26 socket region and direct communication of the sinus with the oral cavity

chance of healing of OAC is decreased and may progress to OAF.

Among patients who do not follow the post-extraction instructions or where the clot is deficient/gets dislodged, chances of OAF are increased in susceptible cases. Failed sinus lift procedures, ailing and failing implants and periimplantitis are all potential causes for causing OAF.

\subsubsection{Clinical Features}

1. Primary complaints in established OAF cases are mainly oronasal regurgitation and burning sensation in sinus on having food.

2. Patients may visit the ENT surgeon with complaints of acute sinusitis, secondary to infection of sinus via unrecognized OAF.

3. In certain cases, there may localized pain, tenderness, foul smell, unpleasant tasting discharge, persistent nasal discharge and post-nasal drip.
4. In long-standing untreated cases, there will be clinical and radiological features of chronic sinusitis. The antral lining will undergo thickening/hyperplasia, and eventually, sinus gets obliterated or there may be evidence of sinus polyps.

I have seen a case where the patient was referred with a protruding sinus polyp through the socket of an untreated OAF in a maxillary molar site (Fig. 24.9a and b). In this particular case, a root was displaced into the sinus as well. It was not sure whether this polyp ensued secondary to OAF or whether pre-existing sinus polyp leads tothe OAF.

We should also be aware that antral malignancies may protrude through the unhealed socket of maxillary molars. Most of the times, the surgeon being ignorant of the disease would have extracted the tooth due to mobility caused by the erosion due to the malignant lesion, and a few weeks after, the patient may present, with the lesion protruding through the socket (Fig. 24.10). 

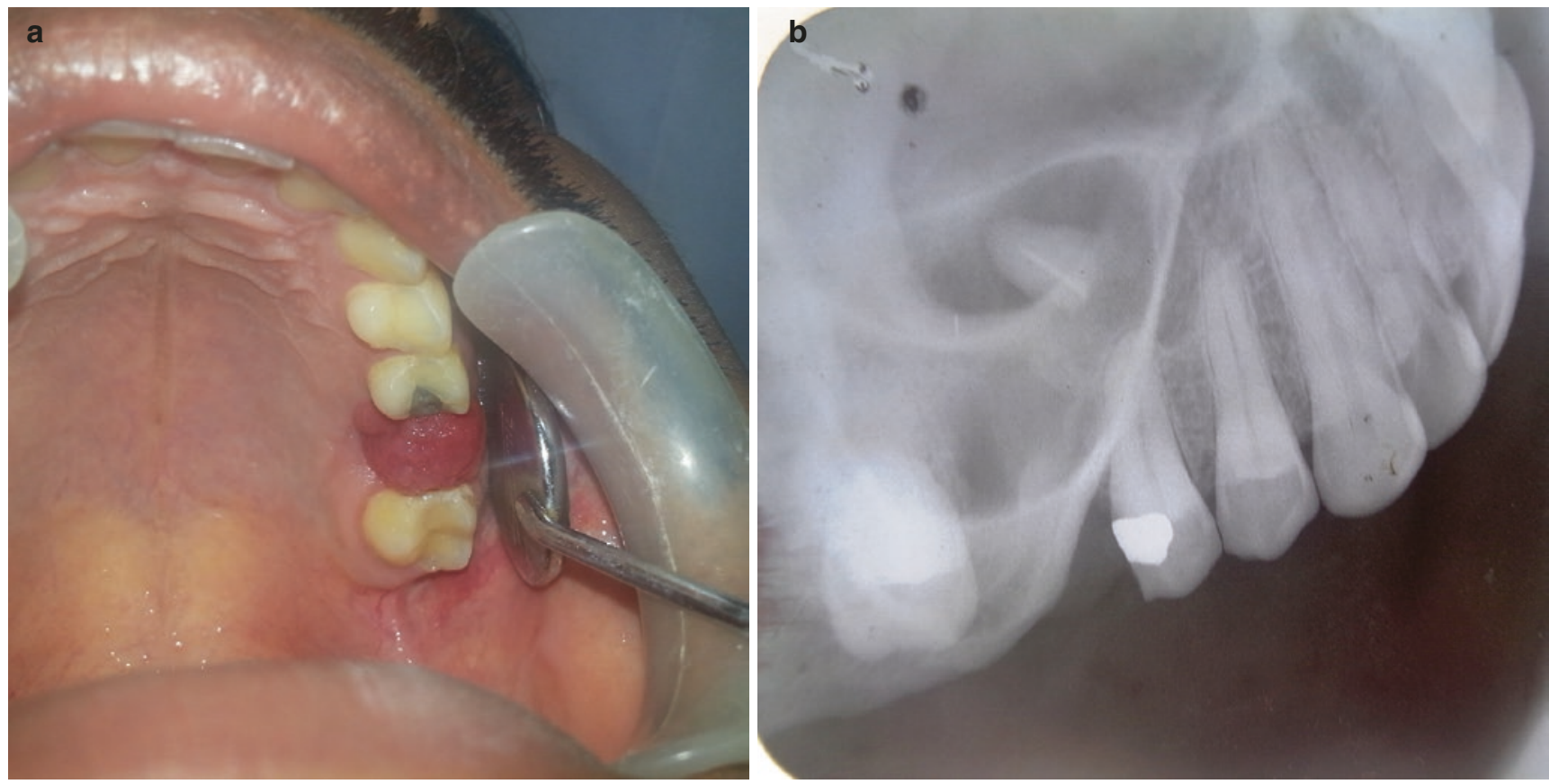

CAssociation of Oral and Maxillofacial Surgeons of India

Fig. 24.9 (a) Clinical picture showing an antral polyp protruding through the sinus. Some clinicians may consider this to be a Post-extraction granuloma possibly of a reactive nature due to the root in the sinus. (b) Occlusal X-ray view showing root in the sinus

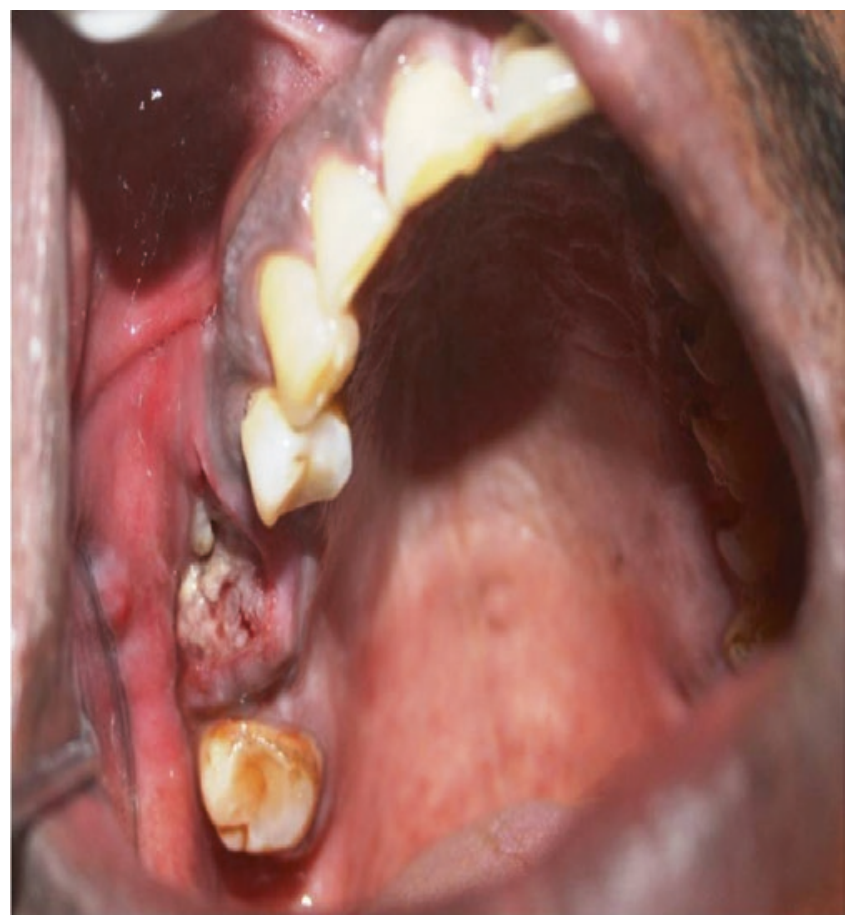

CAssociation of Oral and Maxillofacial Surgeons of India

Fig. 24.10 A case of extraction of upper right second molar due to mobility by dental surgeon, who was unaware of the cause of mobility being antral malignancy. Couple of weeks after extraction, the lesion was seen protruding through the socket

5. The mucosal edges of the socket will be rounded off, and an evident opening may be seen via the socket into the sinus.

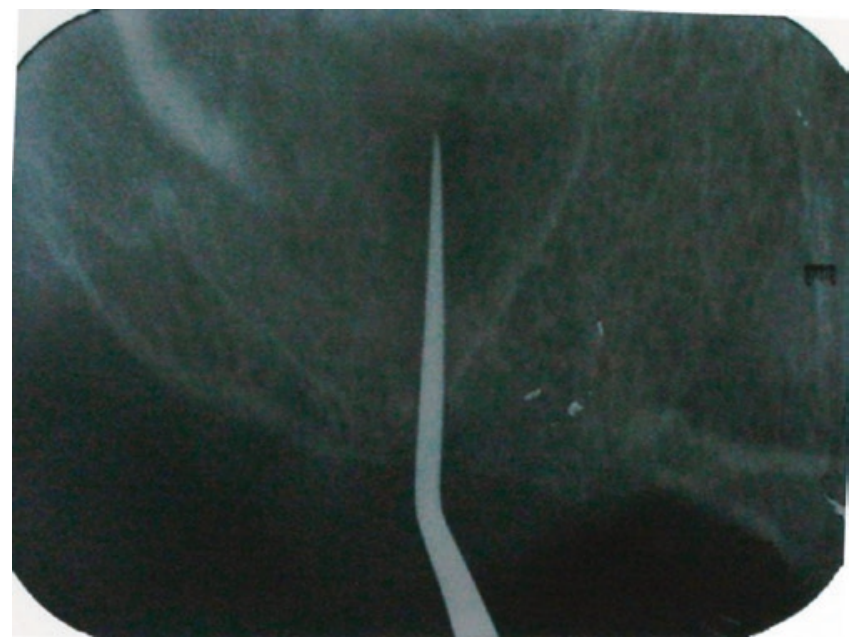

CAssociation of Oral and Maxillofacial Surgeons of India

Fig. 24.11 IOPA $x$-ray showing metal probe entering the sinus via a minute unhealed OAF defect

6. In certain cases, the ridge will clinically look well-healed; however on careful probing, an unhealed tract will be seen, leading to the sinus (Fig. 24.11).

\subsubsection{Confirmatory Tests of OAF}

1. Holding water in the mouth and exerting pressure with mouth closed may elicit oronasal regurgitation.

2. Hold a piece of cotton wisp with tweezers at the OAF opening site, and request the patient to blow through the 
nose with the nostril closed. The wisp will vibrate under the flow of air via the OAF (cotton wisp test/butterfly test).

3. The patient may find it difficult to hold pressure within the sinus, and a whistling sound may be appreciated by the examiner during the Valsalva manoeuvre.

4. Holding a mouth mirror near the opening of OAF will cause fogging of the mirror.

5. Place the nozzle of the suction at the opening of the fistulae. A sound similar to blowing through the mouth of an empty bottle may be heard.

\subsubsection{Treatment Modalities for OAF}

Techniques for OAF closure have evolved over a long period of time and have a robust history. Many techniques have been time tested and well-established, form the mainstay of OAF closure and will be discussed in this section. Literature is replete with various technical modifications; it is not possible to discuss all these in detail and will be beyond the purview of this chapter. The reader is advised to look into the references if a thorough review of techniques is required [3, 4]. Figure 24.1, in reference [4] (Visscher et al. JOMS 2010), gives an excellent overview of the various treatment modalities for oroantral communications Awang et al. [5] back in 1988 have published an excellent review of techniques, which were established at that time.

Since a plethora of techniques are available, the surgeon has the freedom to choose the technique, which works well in his hands based on the training received and surgical competence. One cardinal rule, which may be followed in OAF closure, is to start with the simplest technique available and reserve the complex technique in case the first attempt fails. A sequential option may be followed, the patient is to be warned that there are chances of failure and a secondary or tertiary surgery with more complex techniques may be required at times.

At this stage, it is worth remembering a quote which I have come across somewhere: "Re-operation after past failures at the hands of other surgeons should be approached with due humility".

The options for treatment can be broadly categorized under the following headings:

- Local flaps.

- Regional flaps.

- Combined with autografts.

- Combined with allografts.

- Prosthetic options.

The most widely used local flaps can be classified as

1. Buccal advancement mucoperiosteal flap (Moczair flap/Rehrmann flap/Berger flap).

2. Buccal advancement flap with buccal fat pad grafting (Two-layer closure).
3. Palatal pedicled flap (Ashley's rotational flap).

4. Tongue flaps: anterior and posterior based.

The multitude of techniques and variations has made the literature on OAF closure a trifle confusing. It is interesting to know that even third molar auto transplantation has been found to be successful in closure of immediate OAC (Kitagawa 2003) [6].

In this chapter, we will only be discussing the time tested and commonly performed buccal/palatal flaps with a reasonable amount of success rate. The tongue flaps are a second option, but the difficulty is caused to the patient in the postoperative period until the pedicle is divided and the need for patient compliance, difficulties in feeding, mastication; speech and maintenance of oral hygiene should be taken into consideration before performing them.

As there are multitude of variations and modifications in OAF closure techniques, the author feels that it is wise to present all the relevant modifications in a sequential order (Box 24.1). If the reader refers to the historical evolution of techniques given in the box format, it is evident that different flap designs have been advised ranging from advancement, sliding, pedicled, rotation, bridge, hinged, transverse buccal, double flaps, island flaps, bipedicled flaps, submucosal connective tissue flap, osteoperiosteal flaps, buccinator myomucosal flaps, etc. Each technique has been presented with its own indications and advantages. The reader is advised to read individual publications to get details of these techniques if required.

Irrespective of the technique used, the success of the closure warrants that the basic sound principles of mucoperiosteal flap design are used. The flap should have adequate blood supply, should be handled gently, and should lie in the advanced position without tension.

\subsubsection{Assessment of OAF}

The following factors should be assessed while planning the technique of closure in an OAF.

Size of the communication (Bone defect is always bigger than the visualized soft tissue defect)

- Location of defect.

- Health of the sinus/presence of infection.

- Time of diagnosis of fistula.

- Condition of tissue available.

- Amount of tissue available.

\subsubsection{Objectives in Treatment of OAF}

When treating an OAF, the surgeon should have the following objectives in mind [7]. (This can be called the 4 E's).

1. Elimination of the antral pathology.

2. Elimination of the epithelial lining of the fistulous tract. 
3. Establishment of stable closure of fistula.

4. Establishment of satisfactory drainage.

\section{Box 24.1 Historical Evolution of OAF Closure Techniques}

- Welty CF 1920: buccal mucoperiosteal flap [8].

- Moczair 1930: buccal sliding trapezoidal flap [9].

- von Rehrman 1936: vestibular buccal mucoperiosteal flap [10].

- Berger 1939: Buccal advancement flap [11].

- Ashley 1939: palatal rotation flap [12].

- Kruger GO 1984: V-shaped excision of lesser curvature of palatal rotation flap [13].

- Kazangian 1949: bridge flap [14].

- Mc Clung 1951: tantalum foil [15].

- Schuchardt 1953: transverse buccal flap [16].

- Guerrero- santos 1966: Tongue flaps for OAF [17].

- Rintala 1971: palatal hinged flap (inversion/reverse palatal flap) [18].

- Zeimba 1972: double flaps (reverse palatal \& buccal [19]).

- Meyerhoff 1973: gold foil [20].

- Henderson 1974: palatal island flap [21].

- Choukas 1974: Palatal rotational advancement flap [22].

- Gullane P 1975: modified palatal island flap, relieved vessel at greater palatine foramen [23].

- Cockerham 1976: Bone grafting [24].

- Egeydi 1976: bucket handle flap (bipedicled buccal flap) [25].

- Egeydi 1977: Buccal fat pad and split thickness graft [26].

- Sachs 1979: posteriorly based lateral tongue flap [27].

- Ito \& Hara 1980: submucosal connective tissue pedicle palatal flap [28].

- Quale 1981: double flap [29].

- Brusati 1982: osteoperiosteal flap + vestibule mucoperiosteal flap [30].

- Al sibahi 1982: used soft polymethacrylate [31].

- Mitchell 1983: used collagen [32].

- Carstens MH 1991: anteriorly based buccinator myomucosal island flap [33].

- Zide 1992: Hydroxyapatite block closure [34].

- Shaker 1995: used Zenoderm [35].

- Hanazawa 1995: pedicled fat pad graft [36].

- Hori M 1995: Deans extended interseptal alveolotomy technique [37].

- Paul salins 1996: anteriorly based palatal flap [38].

- Pandolfi 2000: Three layer closure of oroantral cutaneous defect-palatal flap + buccal fat pad + skin flap [39].
- Lee JJ 2002. Repair of OAC in the third molar region by random palatal flap [40].

- Haas 2003: Monocortical bone grafts [41].

- Kitagawa 2003: third molar transplantation [6].

- Ogunsalu 2005: GTR membrane [42].

- Martin S 2008: metal plates and aluminium foils [43].

- Visscher 2010: biodegradable polyurethane foam [44].

- Sandhya 2016: Resorbable GTR Membrane and FDMB Sandwich Technique [45].

- Ram H 2016: used auricular cartilage [46].

\subsection{The Buccal Advancement Flaps}

The names of Moczair, Berger and von Rehrman have been used interchangeably when speaking of buccal flaps in the literature. The buccal flap designed by Moczair [9] was a sliding trapezoidal flap, while the ones designed by Berger [11] and Von Rehrman [10] were buccal straight advancement mucoperiosteal flaps.

Von Wowern (1982) [47] in a study of 90 patients compared Moczair with Rehrman flaps and advocated the former for treating OAF in edentulous patients. Killey and Kay (1967) [48] proved the efficacy of buccal flap in a large series of 250 cases. The buccal flap technique can be satisfactorily employed in the treatment of small and medium-sized communications where there is clear sinus lavage through OAF, and proper antral regime has been maintained 4-5 days prior to the surgery.

The technique of raising a buccal flap is given along with the 2 layer BFP closure technical note box (Box 24.2) and is essentially the same. A few words are needed to elaborate on the buccal flap and periosteal scoring. The buccal flap raised is a full thickness trapezoidal (rectangular/4 sided) mucoperiosteal flap. There are 2 releasing incisions, one anterior and one posterior. The incisions are put in such a way that the flap looks tongue/funnel-shaped and is feasible for advancement palatally without tension. Great care is given to raise it gently without causing any 'button holing'/fenestrations in the flap. The base should be broad enough to have good random blood supply, and flap margins should be incised sharply in order to avoid ragged edges. It is the periosteum that gives tension and may prevent advancement palatally. In order for the flap to lie passively, the periosteum alone is scored gently with a number 12 or 15 blade, horizontally at the level of the base of the buccal flap. This will release the tension and help in advancement. The scoring is a fine procedure, and the surgeon should be aware that, if the scoring goes deep beyond the level of periosteum, the mucosa may be incised which may even jeopardize the viability of the flap by affecting the blood supply emanating from the base (Fig. 24.12). 


\section{Box 24.2 Technical Notes of a 2 Layer BFP Closure}

- Anaesthesia.

- Fistula tract excision with No 11 BP blade.

- Curette the granulation tissue.

- Buccal and palatal margin freshened with No 15 blade.

- Palatal margin made into a semilunar shape to accept the buccal flap.

- Flap to rest on sound bone on the palatal side.

- Extended trapezoidal flap placed on the buccal side.

- Posterior vertical release of flap slightly curved towards vestibule to facilitate advancement anteriorly.

- Reduction of alveolar bone height if required.

- Periosteal scoring of buccal flap.

- Posterior periosteum teased open to identify the BFP.

- BFP mobilized gently with non-toothed forceps (blunt dissection, avoid tension).

- BFP sutured to palatal margin with 3 'O' non-cutting vicryl rapide.

- Buccal flap advanced palatally to cover the BFP.

- Buccal flap sutured to palatal margin with horizontal mattress vicryl sutures.

- Anterior vertical release sutured.

- Posterior vertical release usually needs no suturing.

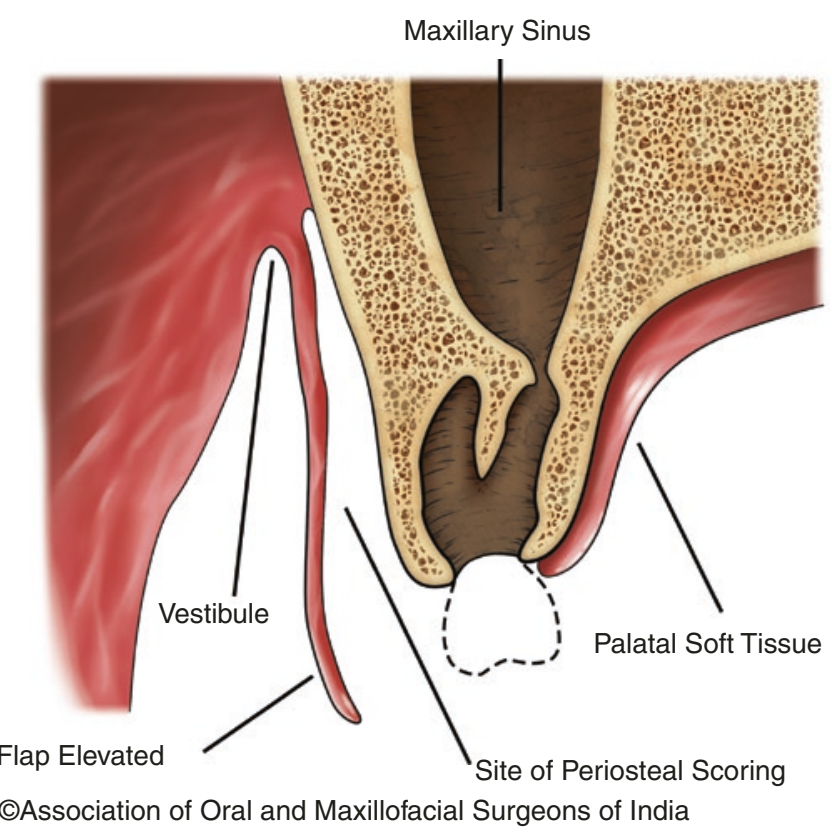

Fig. 24.12 Diagrammatic representation of raising a buccal trapezoidal flap and periosteal scoring
One disadvantage of all buccal advancement procedures is the decrease in the vestibular depth, which may be problematic for prosthetic rehabilitation.

\subsubsection{Step-by-Step Technique of Doing Buccal Advancement Flap + Buccal Fat Pad Grafting (BFP)}

The step-by-step procedure for 2 layer closure technique is given in the box format (Box 24.2). The steps of performing a 2 layer closure are similar to the buccal advancement alone, except that the BFP is raised, advanced and sutured primarily to the palatal edge.

The use of the buccal fat pad (BFP) as a grafting source in the closure of intra-oral defects has gained popularity in the last quarter of the twentieth century. Its use as a pedicle graft for oral reconstruction was first reported by Egyedi in 1977 [26]. Studies have proved through a series of cases that the use of buccal pad fat in the closure of oroantral communications has significantly reduced the failure rate of the treatment. The closure of OAF with single-layered buccal mucoperiosteal advancement flaps (Berger/Reherman) has been well documented in the literature. Without much change in the surgical steps, adding a second layer of BFP will enhance the success rate of closure.

The buccal fat pad (BFP) as an anatomic element was first mentioned by Heister in 1732 and was described by Bichat in 1802 [49]. The BFP (Bichat ball) is an anatomically rounded and biconvex structure that is of great importance in the facial contour. It is an adipose tissue surrounded by a thin capsule

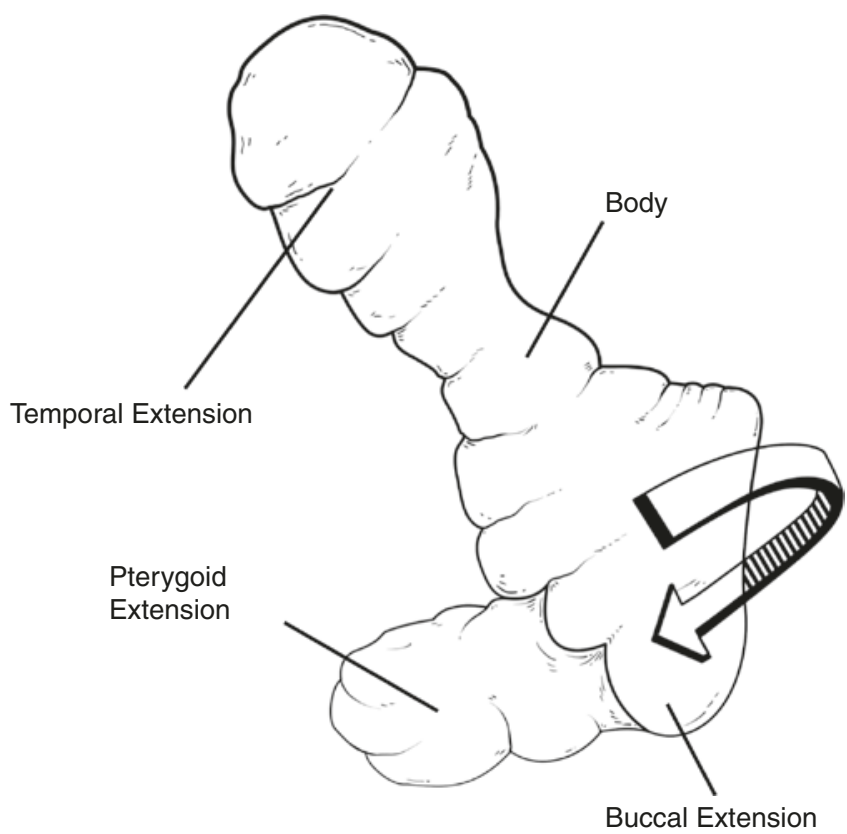

CAssociation of Oral and Maxillofacial Surgeons of India

Fig. 24.13 Anatomical representation of the buccal fat pad 
and located inside both masticatory spaces in the oro-maxillofacial region (Fig. 24.13). The BFP has a central body with four extensions: pterygopalatine, temporal, pterygoid and buccal. The central body and buccal extension account for approximately $50 \%$ of the BFP and are the most clinically significant portions. The BFP has a $10 \mathrm{~mL}$ volume, a thickness of $6 \mathrm{~mm}$ and an approximate weight of $9.3 \mathrm{~g}$. The BFP is surrounded by a thin fibrous capsule. Blood supply is provided by the vestibular and deep branches of the maxillary artery, the transverse facial branches of the superficial temporal artery and branches of the facial artery. The rich blood supply may explain the high success rate. It also may be one reason for the quick epithelialization of the fat. The buccal fat pad is a mass of specialized fatty tissue called as syssarcosis, a fat that enhances muscular motion. It is distinct from the subcutaneous fat and shows marked similarity to the orbital fat. It can easily cover small to medium sized defects of about $4 \mathrm{~cm}$ in diameter. When properly dissected and mobilized, the BFP provides $7 \times 4 \times 3 \mathrm{~cm}$ of a pedicled graft. (Box 24.3).

\subsubsection{Clinical Pictures Demonstrating 2 Layer Closure Technique with BFP (Fig. 24.14a, b, c, d and e) [50]}

Figure 24.14a, b, c, d and e: Reprinted with permission from springer nature customer service centre $\mathrm{GmbH}$ : springer publisher: Journal of maxillofacial and oral surgery: The versatility in the use of Buccal Fat Pad in the closure of oroantral fistulas. Suvy Manuel et al. [COPYRIGHT 4524640093264] (2015).

Box 24.3 Advantages of Buccal Fat Pad

- Easy access

- Relatively easy to perform.

- Minimum dissection.

- Great versatility.

- Good mobility.

- Reliable blood supply.

- Low rate of complication.

- No donor site morbidity.

- Low risk of infection.

- Shortened surgical time.

- No scar.

- Fast cover by epithelium.

- High success rate.

\subsection{Palatal Rotational Flap (Ashley's Flap)}

Among palatal flaps, there are 2 main types: The palatal straight advancement flap (Fig. 24.15) and the palatal rotational flap (Fig. 24.16).

However, the palatal rotational flap proposed by Ashley in 1939 [12] has stood the test of time. It is a pedicled flap, posteriorly based on the greater palatine vessel. A tongueshaped full thickness mucoperiosteal flap is raised on the side of the OAF. The OAF site is freshened, and the fistula is excised as a preparation to receiving the flap. The flap is rotated and sutured on to the OAF site. In order to avoid kinking at the site of rotation near the palatal margin of the socket, a V-shaped area may be excised (Kruger's [13] modification). The raw site is packed with dressing to allow secondary healing. This is a thick, bulky and vascular flap, which is quite reliable and serves often as a second line of defence when the buccal advancement flap fails. Different authors have given various names for this flap-like rotational, advancement and transposition.

Other types of palatal flaps mentioned or published in the literature are the palatal island flaps (Henderson 1974 [21]), palatal hinged/inverted/reverse flap (Rintala 1971 [18]) and sub-mucous connective tissue flap (Ito \& Hara 1980 [28]). Palatal flaps are also used as part of double flap techniques as proposed by Zeimba in 1972 [19] and Quayle in 1981 [29].

\subsection{Importance of Timing of Closure of OAF}

The health and status of the socket edges and margins play an important role in deciding the success of the closure, irrespective of the surgical technique used. An OAF, which is well-rounded margins and does not show any evidence of oedema/inflammation, is a good recipient area for the closure. Oral surgeons may often get referred cases with history of difficult extraction of maxillary molars/attempted removal of fractures root tips/cases with established OAC and/or with missing root tips. Often, the socket may show evidence of traumatic extraction with ragged margins, tissue loss, irregular bony edges, congestion, tenderness and oedema. Such sites are not favoured for an OAC/OAF closure, and surgeons should not be tempted to attempt a closure. The chances of failure of the closure are high due to unhealthy mucosal condition and its prudent to wait for a couple of weeks for good healing of the wound edges and then consider closure. It may be argued that the sinus health may deteriorate during this waiting period, and all these are decisions to be taken by the surgeon on their individual merit (Fig. 24.17a and b). 

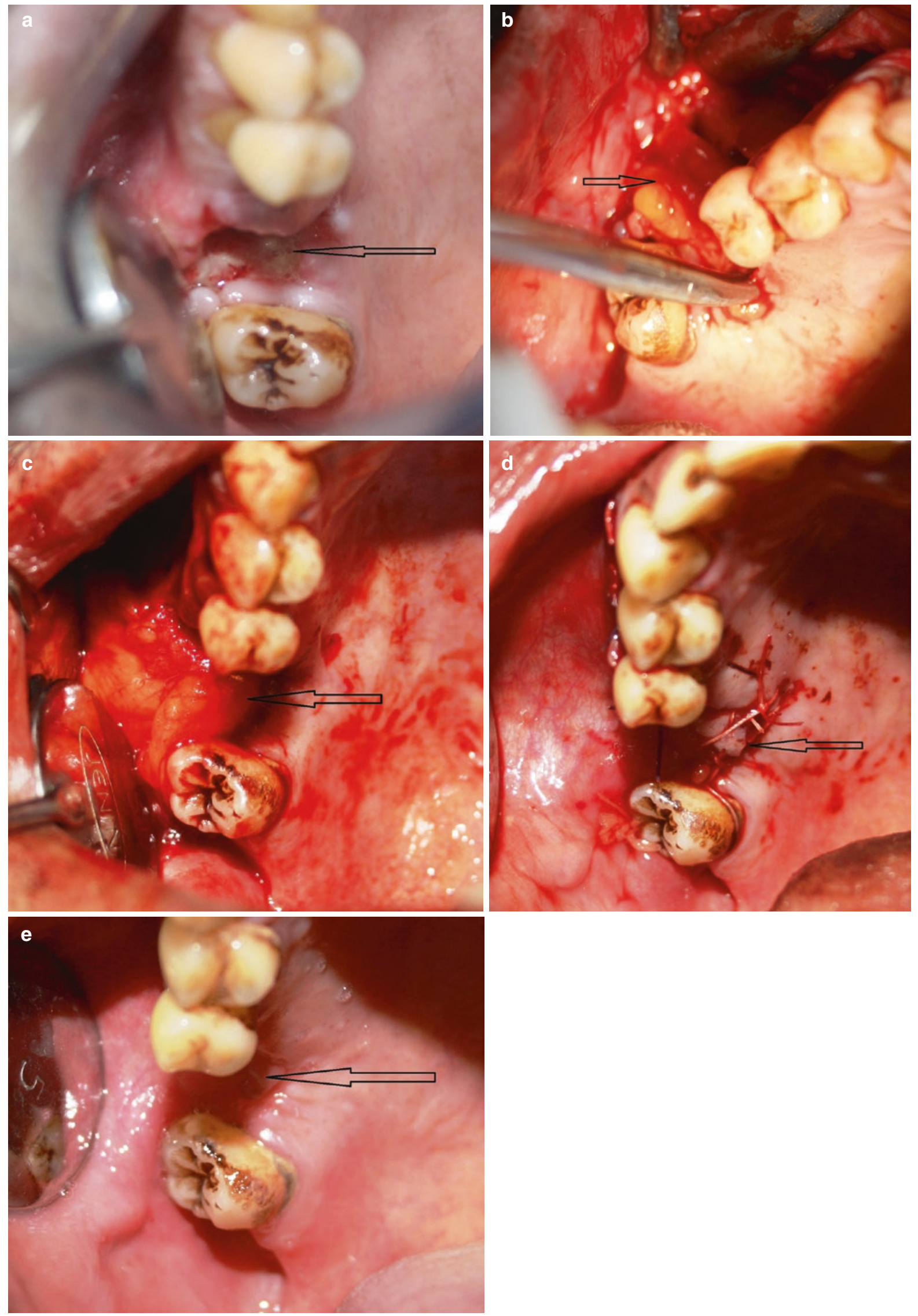


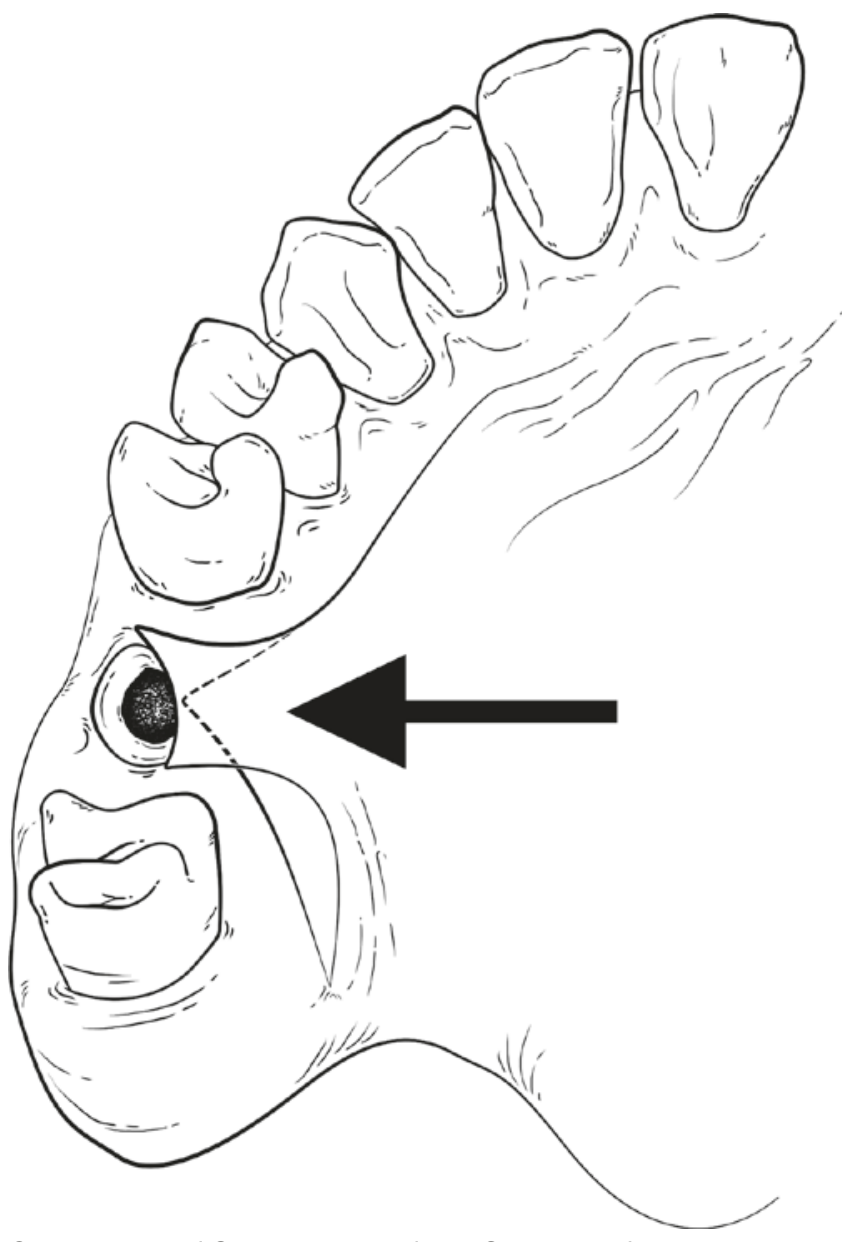

CAssociation of Oral and Maxillofacial Surgeons of India

Fig. 24.15 Diagrammatic representation of a palatal straight advancement flap

\subsubsection{Role of Health of Sinus and Antral Regime}

Depending upon the duration of OAF, the sinus may be in various stages of disease. In acute OAC, unless there is preexisting disease, the closure may be attempted with a fair

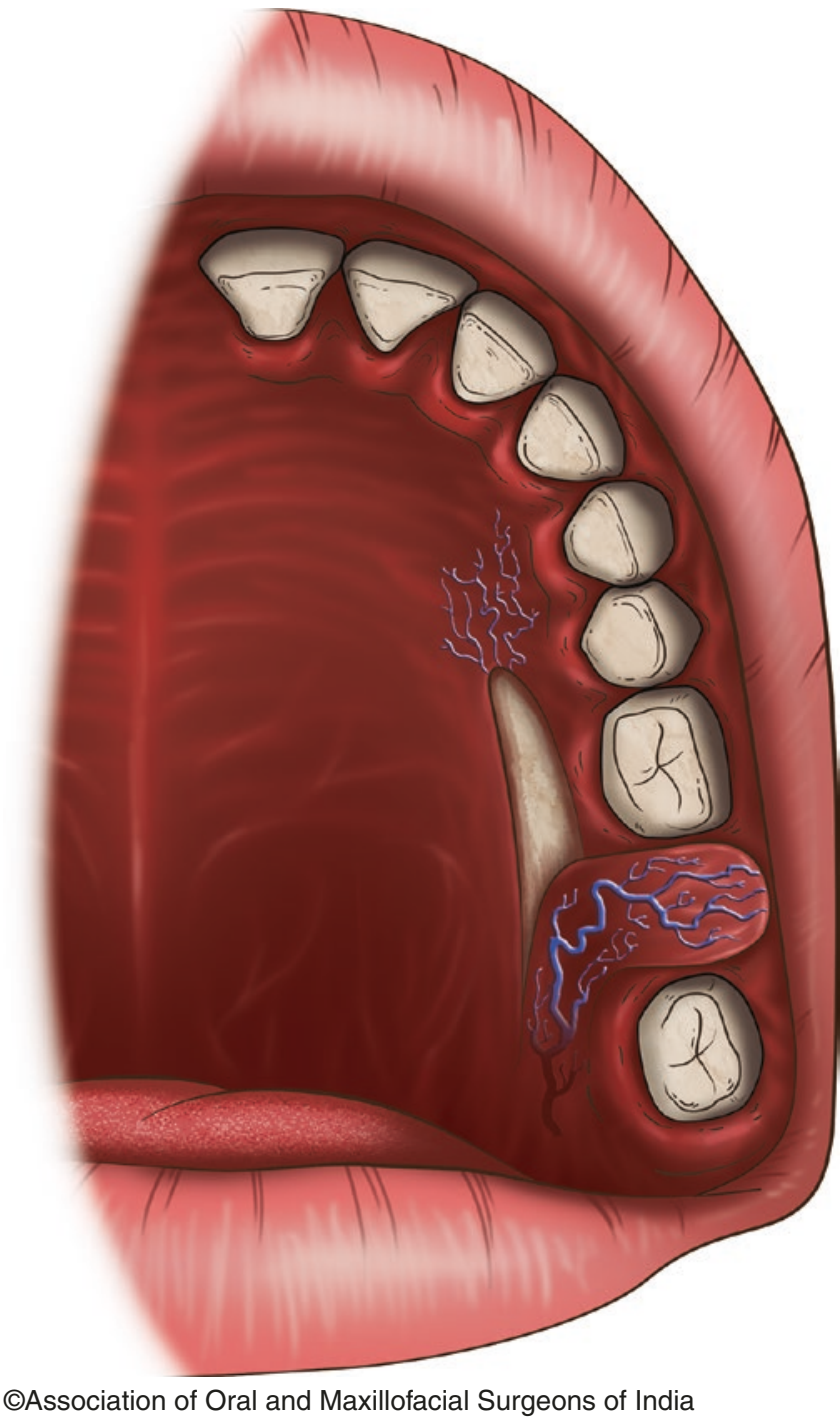

Fig. 24.16 Diagrammatic representation of a palatal rotational flap

chance of success. In untreated cases of OAF, patients may have acute episodes of sinusitis or progress into a chronic stage manifesting thickened antral lining and fluid/exudates/ pus collection in sinus or antral polyps. In cases of acute nature, the sinusitis has to be under control before closure (Fig. 24.18).
Fig. 24.14 (a) Oroantral fistula seen at the maxillary right first molar extraction site (b) Buccal fat pad being teased out from the buccal vestibule. (c) The buccal fat pad being advanced and sutured to the palatal margin. (d) The buccal mucoperiosteal flap sutured to the palatal margin and covering the buccal fat pad. (e) Excellent healing of the closure site (2 month post-operative view) [50] 

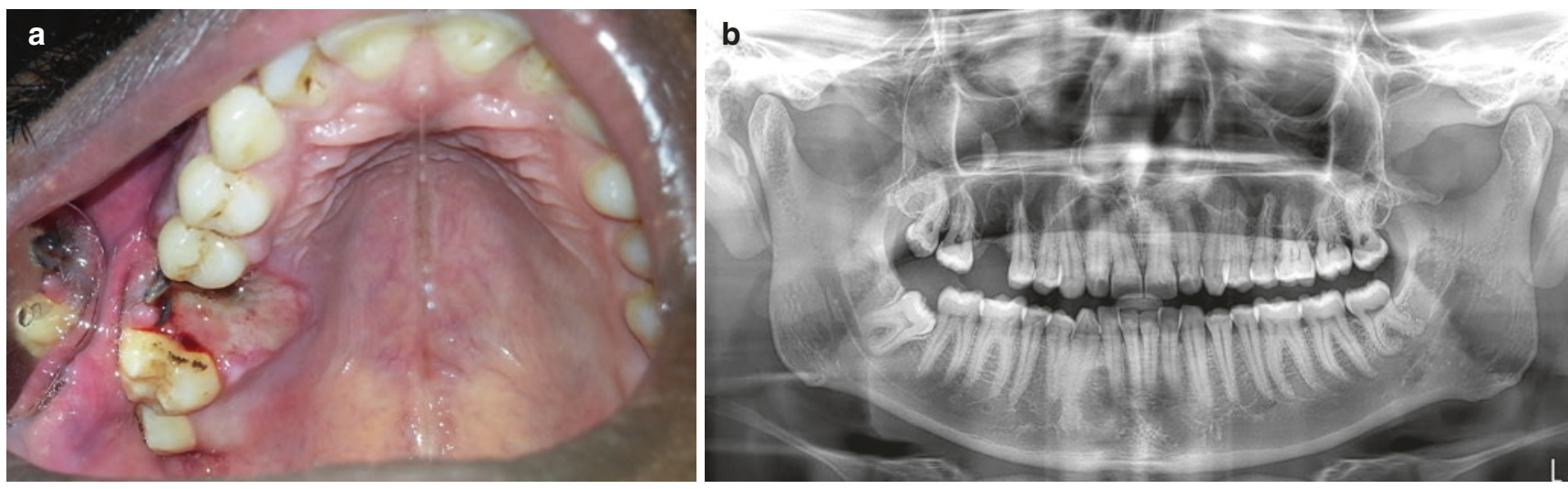

CAssociation of Oral and Maxillofacial Surgeons of India

Fig.24.17 (a) Clinical picture of a referred case in a 30-year-old male, who had a traumatic extraction of upper right first molar 1 week back. One complete root has been pushed into the sinus (see OPG, Fig. 24.17b). Note the traumatized, congested, oedematous and ragged

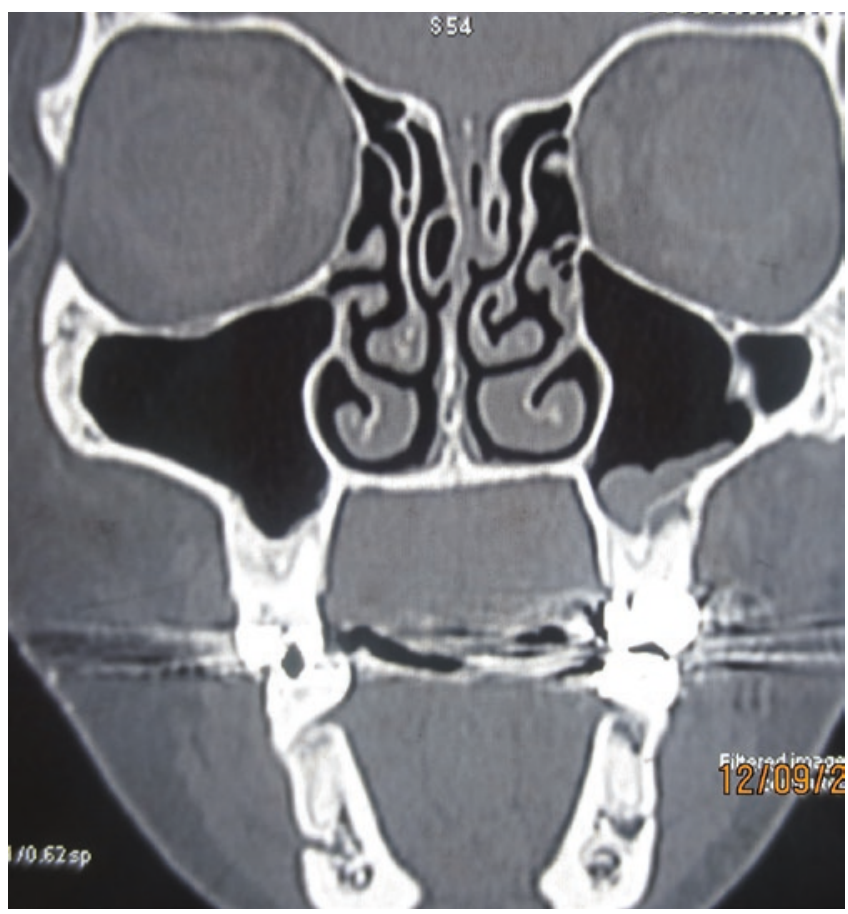

CAssociation of Oral and Maxillofacial Surgeons of India

Fig. 24.18 A coronal CT scan, showing periapical widening/lesion in a maxillary left molar, which is close to the sinus floor and reactive sinus lining thickening in that region. Possible OAC resulting from this extraction may have a decreased chance of success after immediate closure

\subsubsection{The Antral Regime}

Antral regime is usually helpful, which is usually started about 5-7 days before the anticipated closure. It includes.

1. Antibiotics to control sinusitis.

2. Anti-inflammatory agents if required.

3. Steam inhalation at prescribed intervals. sutured wound edges/tissue loss and slough in the palatal tissue. He is not a candidate for closure immediately. It is preferable to wait until complete healing and schedule the procedure electively. (b) OPG of the above case showing the root in the sinus cavity

4. Nasal decongestant drops to increase the drainage of the sinus and open up closed ostium.

5. Antihistamines to decongest the sinus and also to avoid sneezing, which may increase the sinus pressure and have a deterrent effect on the success of the closure.

The antral regime may be continued for a few days (3-7 days) after the closure as well to ensure a trouble-free healing. After closure, the patient is advised to have certain restrictions in the initial healing phase, in order to avoid break down of the closure, i.e.

1. Avoid vigorous sneezing/coughing/blowing through the nose.

2. If coughing cannot be avoided, do cough with mouth open.

3. Avoid smoking to avoid negative pressure in the oral cavity.

4. Avoid using straws to drink fluids.

5. Avoid vigorous gargling or swishing in the oral cavity.

6. Do not disturb the surgical site with tongue movements.

7. It would be preferable to review the patient at least once in 2-3 days during the initial healing period to assess the healing status. The clinician may irrigate the surgical site with saline removing the collected debris/ slough if any.

8. Some author's advice to keep a pre-fabricated custommade acrylic splint at the site of closure as a support.

However, there are thoughts that the splint may irritate or traumatize the sutured edges on the alveolar ridge and be a deterrent for the healing.

\subsubsection{Antral Lavage}

At times, the antral lavage is done daily or on alternate days along with the antral regime to clear the exudate from the 


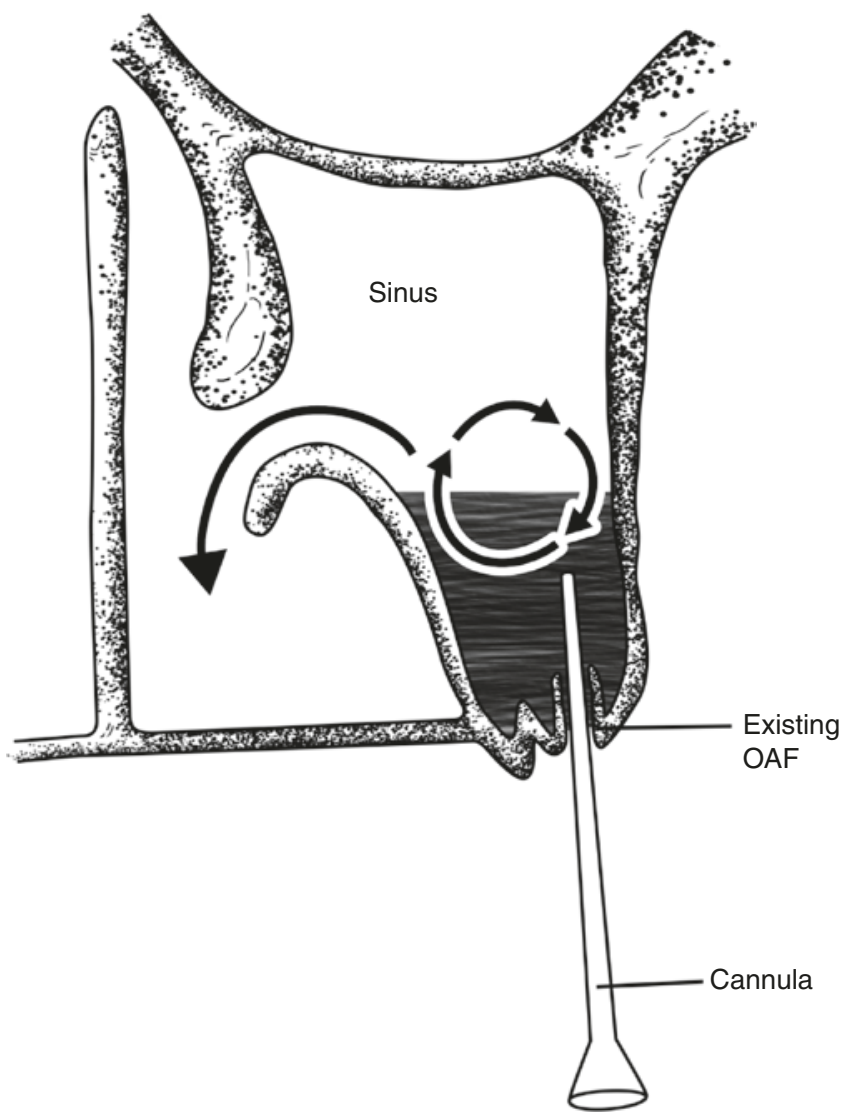

CAssociation of Oral and Maxillofacial Surgeons of India

Fig. 24.19 Diagrammatic representation of antral lavage via the existing $\mathrm{OAF}$

sinus. The presence of exudate/pus can be seen as a 'fluid level' in a paranasal sinus X-ray, or there may be generalized opacification of the involved sinus in the X-ray. The closure is attempted, only when the surgeon feels that the antral washouts are clear, and the sinus is reasonably healthy to receive the closure.

ENT books describe different methods of antral lavage, either via a Caldwell Luc opening or via the nasal meatus depending upon the case. However, from an oral surgical perspective for most cases, antral lavage may be done via the existing OAF (Fig. 24.19). 10-20 ml of saline is flushed through the OAF via a syringe, and patient is seated at a forward position with head bent down. The washout will flow out through the nasal cavity or via the OAF, and the washout is collected in a tray positioned before the patient. In the initial days of lavage, the washout will have a cloudy/opaque appearance, and after few days, we should expect the washout to be clear.

\subsection{Caldwell Luc Procedure}

This procedure was developed independently by two surgeons, George Caldwell in New York (1893) and Henry Luc in Paris (1897) (Box 24.4).
Box 24.4 Technical Note: Caldwell Luc Procedure in Oral Surgery Context

- Upper lip retracted.

- Horizontal U-shaped incision in the vestibule-few $\mathrm{mm}$ above gingival attachment or

- Mucoperiosteal flap-raised upward to the point of emergence of the infra-orbital nerve.

- Do not damage infraorbital nerve

- Chisel or dental bur is used to create a window on anterior wall of sinus above root of teeth of that area.

- Opening enlarged using Rongeur's forceps until it is of the size of an index finger.

- Sinus exposure gained and required procedure performed.

- Soft tissue placed and sutured over bone with resorbable sutures.

- Good closure is important as the dehiscence itselfwill cause an OAF.

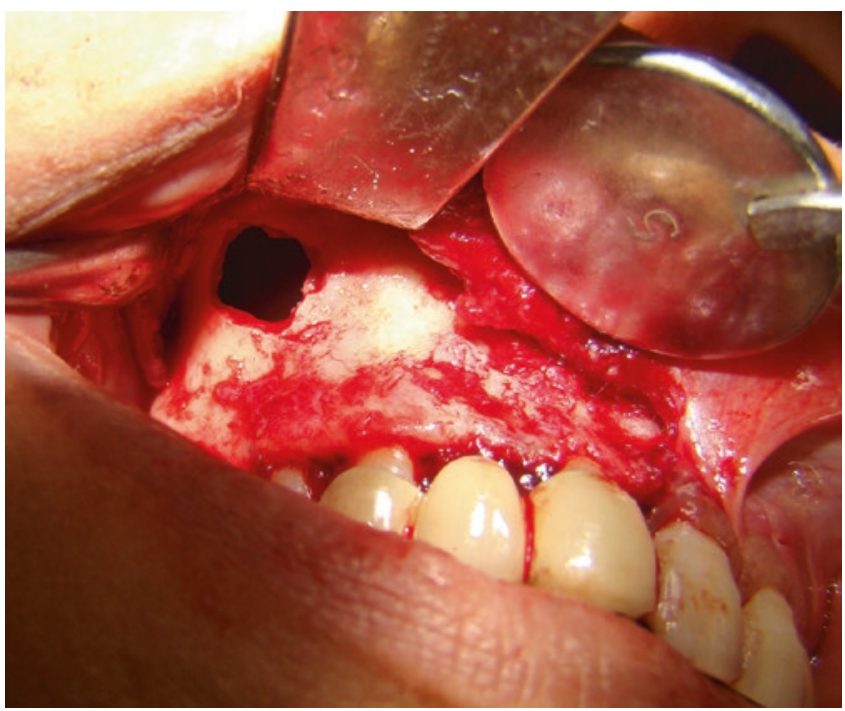

CAssociation of Oral and Maxillofacial Surgeons of India

Fig. 24.20 Clinical picture showing a Caldwell Luc procedure via extended crevicular flap for removal of a root in sinus. Note the defect made in the anterior maxilla wall

It involves making an opening in the anterior wall of sinus in the canine fossa region, to get good access to the sinus. The procedure is done either via a sublabial incision or by extended crevicular incisons (Fig. 24.20). In the context of OAF, this approach has relevance when combined along with the closure of OAF. The approach may be used to retrieve root tip or to surgically treat chronic sinusitis as in polyps. In combined cases, the extended crevicular flap with adequate releasing incisions may be used to remove root tip and may 
be used as a buccal advancement flap with or without buccal fat pad graft for the closure of OAF.

The indications for Caldwell Luc procedure are given below:

1. Recovery of entrapped foreign body from the sinus cavity proper, displaced tooth or root.

2. Excision of sinus polyps, tumours and cysts.

3. Treatment of blowout orbital fracture.

4. Management of haematomas of antrum.

5. Chronic maxillary sinusitis.

6. Neoplasm of maxillary sinus.

7. Removal of impacted canines.

\subsection{OAF with Chronic Sinusitis}

Such cases are more difficult to manage and will need a combined oral surgery/ENT approach. There may be severe antral lining hyperplasia and lack of natural drainage by blockage of the ostium or antral polyps. The line of management has to be decided on an individual basis. Occasionally, the sinus problem may have to be addressed before attempting a closure, which may require two surgeries. Sometimes, the oral surgeon may be in for a surprise during OAF closures to see fungal balls in the sinus. The reasons for $\mathrm{c} / \mathrm{c}$ sinusitis should be evaluated and addressed accordingly.

The second option is to attempt closure along with the treatment of chronic sinusitis. In such cases, a formal Caldwell Luc opening may be made to remove the unhealthy lining. If that is the case, the buccal flaps are modified as per requirement to get a tension-free closure at the OAF site. In situations where FESS is used, oral surgeon can visualize the sinus and see the OAF from the nasal/antral side. The use of FESS gives a two pronged approach, i.e. the unhealthy lining from the antral side of the OAF can be removed and closure performed. This means that in OAF with c/c sinusitis, a general anaesthesia will be necessary, unlike uncomplicated OAF cases where most of the established techniques may be done under local anaesthesia if required.

Adams (2015) [51] has reported on the success of using combined FESS and BFP closure. The sequence followed by Adams included pre-operative computed tomography, antibiotic therapy, exploration and removal of sinus pathologic tissues, rotation of a pedicled fat pad graft into the oral opening, repair and closure of oral mucosa, exploration of involved sinuses with excision of sinus and nasal tissues necessary for establishment of osteomeatal drainage and follow-up.

Cases of fulminant pansinusitis have been encountered arising from long-standing untreated OAF. This involves the contralateral side, and such cases need a comprehensive joint approach with the allied specialities, before embarking upon closing the OAF.

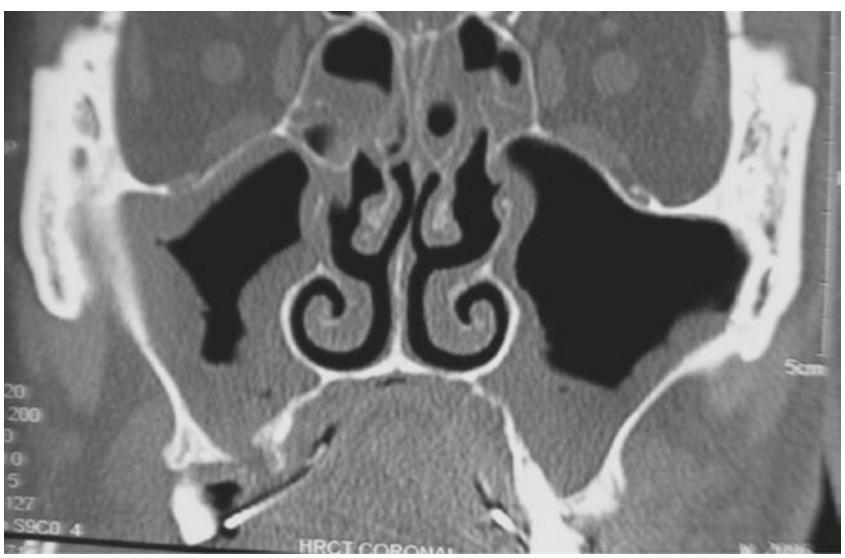

CAssociation of Oral and Maxillofacial Surgeons of India

Fig. 24.21 Coronal slice CT scan, showing hyperplasia of sinus lining, especially on the right side, where the OAF can be Appreciated

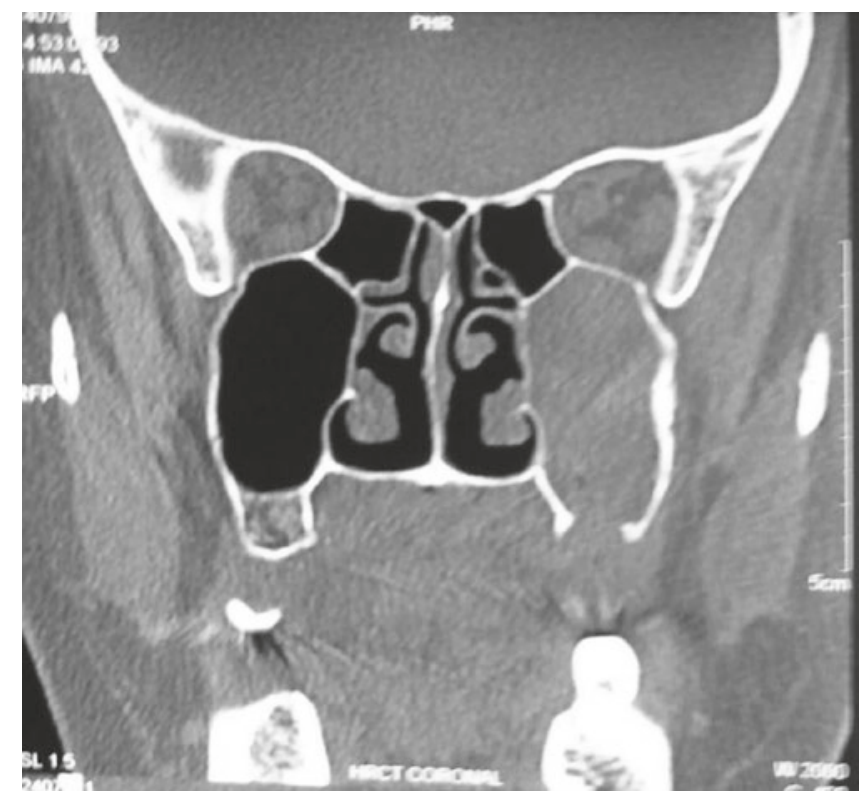

CAssociation of Oral and Maxillofacial Surgeons of India

Fig. 24.22 Coronal CT scan of a 50-year-old male, who had normal extraction of upper left second molar, which was followed by break down of clot and resulted in OAF. He later developed infection with pus discharge from socket. CT scan shows the fully opacified left sinus. Under GA (joint case with ENT surgeon), a 2 layer BFP closure was done, accompanied by FESS and Caldwell Luc approach via extended mucoperiosteal flap. Intraoperatively, the sinus was filled with fungal balls, which could have been the cause for the formation of OAF

Figures 24.21, 24.22 and 24.23 show coronal CT slices of different case scenarios where OAF was accompanied by chronic sinusitis.

In Video 24.1, the video contributing Surgeon has managed an OAF associated with chronic sinusitis, by a combination of Caldwell-Luc procedure, Nasal antrostomy, and layered closure by buccal advancement flap. Layered closure has been achieved by suturing of sub mucosa and mucosa of the advanced buccal flap. 


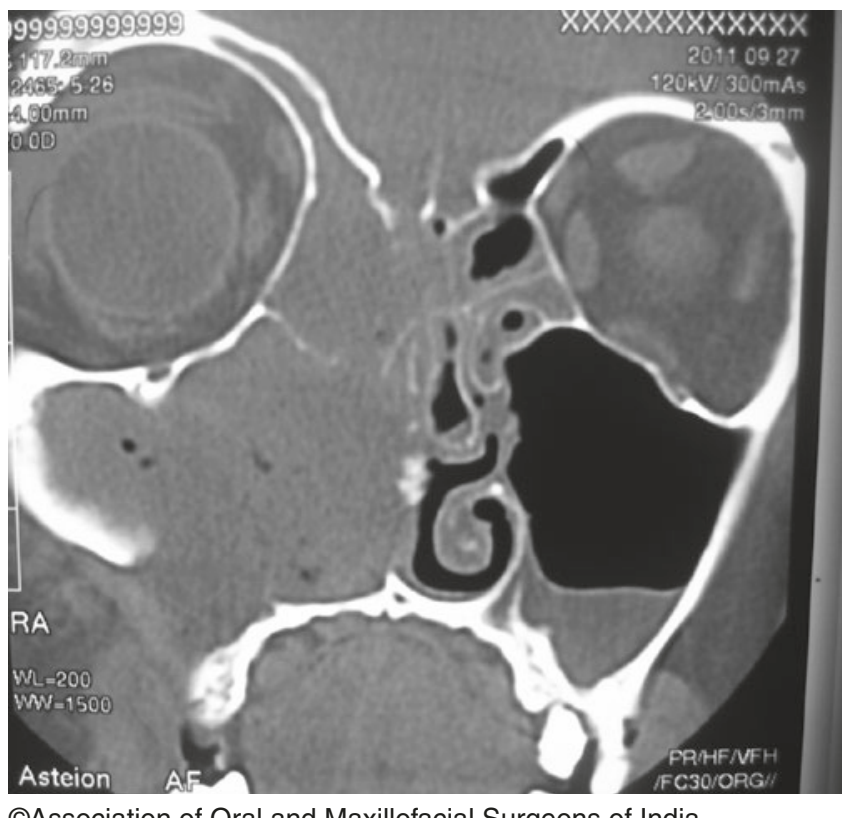

CAssociation of Oral and Maxillofacial Surgeons of India

Fig. 24.23 Coronal CT view showing pan sinusitis in 58-year-old male, who developed an OAF in the anterolateral wall of maxilla from a previous failed surgery, probably for a cyst enucleation in the maxilla (previous records not available)

\subsection{Nasal Antrostomy}

The ostium of maxillary sinus opens into middle meatus, which is at a higher level than the sinus floor (Fig. 24.24). In normal healthy sinus, this is not a problem as the normal ciliated respiratory epithelium will help in the drainage. Briefly saying, nasal antrostomy is a procedure where an opening is made in the inferior meatus, either from the nasal or sinus side to facilitate drainage of sinus in a dependent manner. Nasal antrostomy is an adjuvant procedure, which can be done along with cyst enucleations of the sinus or in selected cases of OAF closure. The need for nasal antrostomy has decreased now with changing philosophies, the advent of FESS and the importance given to the osteomeatal complex. Recent studies (Huang YC [52] 2012) have also proved the decreased need for inferior meatal antrostomy following sinus surgeries.

For elaborate details of Caldwell Luc and nasal antrostomy procedures, readers are advised to refer the concerned speciality books.

\subsection{Root in Sinus}

In situations where a fragment of a root or a full root or roots is missing during extraction of maxillary premolars or molars, the surgeon will have to take certain decisions and some questions should flash through his or her mind.

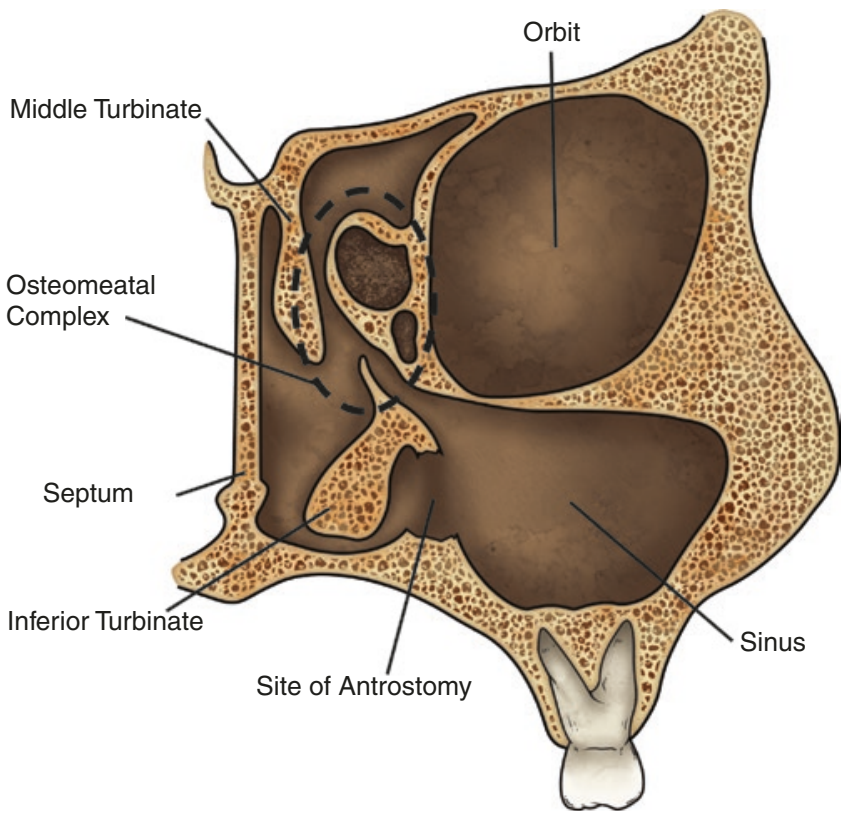

CAssociation of Oral and Maxillofacial Surgeons of India

Fig. 24.24 Diagrammatic coronal section of sinus demonstrating the sinus drainage

(a) Should I locate the root tip and where should I look for it.

(b) If located, should I attempt to retrieve it or decide to leave it.

(c) Will the root retrieval necessitate GA and if so when to schedule the procedure.

(d) Should the root tip left behind be removed later at an elective date or not removed and remove only if any symptoms occur.

(e) If the root has gone into the sinus, an OAC would have been formed. Should I remove the root tip and close the $\mathrm{OAC}$, or should I leave the root tip and close the OAC or plan for a combined removal of root and OAC/OAF closure later on an elective date.

While attempting removal of a root tip, if it suddenly disappears, make sure that the tip is not there in the following places.

(a) Lying freely elsewhere in the oral cavity/vestibules/lingual sulcus.

(b) Tip is not attached with cotton/gauze pieces.

(c) Tip has not stuck to suction drains or bottles.

(d) Tip has not been accidentally swallowed or aspirated.

If the root tip is assumed to be pushed upwards into the sinus cavity, the tip may lodge in the following areas:

(a) A fenestration would have happened in the apical labial/ palatal alveolar bone, and the tip would be lodged between the labial/palatal alveolar bone and the mucoperiosteum. 
(b) Rarely, the tip would have perforated the buccal mucoperiosteum and get lodged near the buccinator muscle.

(c) Tip would be lying between the sinus lining and the sinus floor. In strict sense, it may be assumed that an $\mathrm{OAC}$ is not formed as the integrity of the membrane is not lost.

(d) Tip may have pierced through the sinus membrane and entered the sinus cavity (theoretically causing an $\mathrm{OAC}$ ).

$\mathrm{X}$-rays in two different planes (IOPA/OPG/Occlusal) will be helpful to give an idea about the root tip position especially when it is inside the sinus. When the root tip is retaining its lamina dura on an IOPA x-ray, it may be assumed that it is still lying within the bone and not have entered the sinus cavity. Paranasal sinus view will confirm that the root is in the sinus and CBCT also may be helpful in localization.

In situation (a), Transalveolar approach will help in removing the root tip.

In situations (c) and (d), the following methods are suggested in the literature and the resulting OAC is closed primarily or at a later stage depending upon the surgeons' choice.

1. If the root tip is visible through the socket, it is gently removed with the help of probes/tweezers/mosquito forceps.

2. If not visible, the sinus is flushed with saline and it is hoped that the root tip will float in the sinus. A metal suction tip is placed at the socket apex, and the clinician may expect the root tip to be lodged at the end of the suction tube.

3. A gauze piece may be inserted into the sinus via the socket and pulled out in a jerky fashion hoping that theroot tip will get entangled in the gauze piece.

4. The tip may be removed through the socket, by enlarging the communication. This may require removal of the inter-radicular bone and visualizing the sinus to get better approach, vision and access. This technique is usually successful, but the flip side is that the chance of failure of closure is increased as the surgeon is dealingwith a communication of considerable size (Fig. 24.25).

5. Another option would be to remove the root via the Caldwell Luc approach or FESS. This is usually done on an elective basis.

\subsubsection{Policy of Leaving Root Tip In Situ}

It is important to say a few words on this topic at this juncture, even though there may be difference of opinion and contentions on the points given below. These can be applied to all root tips being left behind. If the clinician

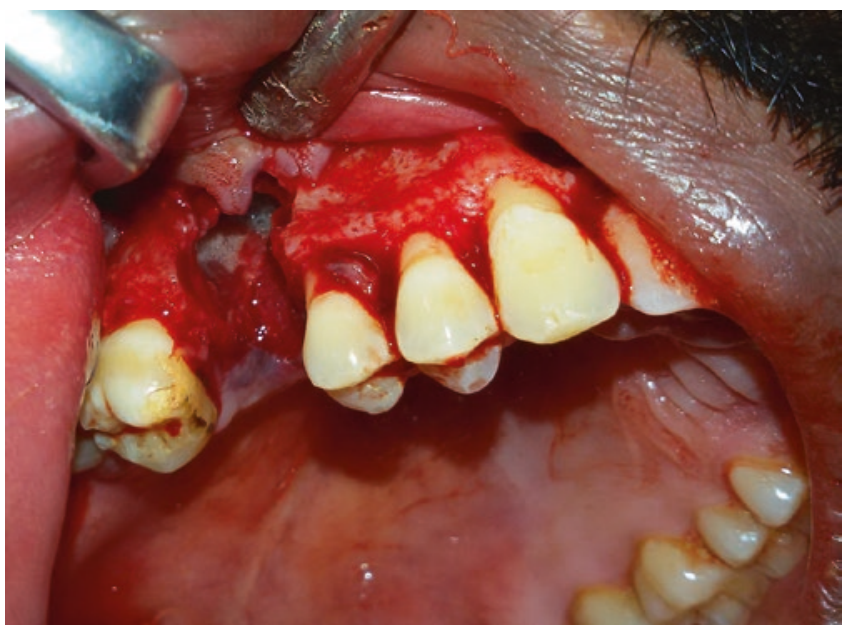

(CAssociation of Oral and Maxillofacial Surgeons of India

Fig. 24.25 In this case, the surgeon is attempting to remove the root in sinus, which has been dislodged superiorly during the extraction, by enlarging the socket and an extended mucoperiosteal flap has been raised. The sinus can be visualized via the socket. This technique is usually not recommended as the resulting OAC will be of considerable size; however, in this case, the OAC was closed by a 2 layer BFP technique

feels that removing a fractured root tip of an upper premolar/molar is beyond his or her level of competence or there is a possibility of causing OAC, which he or she cannot deal primarily, the root tip may be left behind in the following situations;

1. The root tip is less than $2-3 \mathrm{~mm}$ in length.

2. It is not associated with any periapical pathology.

3. It may not interfere with any future prosthetic rehabilitation.

4. Aged/patients with considerable medical co-morbidities.

5. Attempts at removal of the tip may cause more damage and surgical procedures when compared to the benefits of removal.

The patient should be well-informed about this situation and should be informed that the tip may be removed later if they wish so. Adequate documentation in the form of x-rays and clinical notes is mandatory, in order to follow up the case and to avoid any future medico-legal issues.

\section{Clinical Scenario 2}

An interesting clinical Scenario for the benefit of young clinicians.

A 40-year-old female had routine extraction of root stumps of upper left first molar. A pre-operative IOPA was not taken. After extraction, to the surprise of the dental surgeon, there was pus discharge through the socket (See Fig. 24.26a and b) 
The probabilities are that either there was a pre-existing sinusitis, which was unrecognized, or the root stumps caused the odontogenic infection to spread into the sinus.

\section{How will you Manage this Case?}

There may be different opinions, but the following sequence may be followed in this particular case, which is given as clinical pearl section below.

Clinical Pearls (Management of Case in Fig. 24.26a and b)

- Temporary closure of socket and no flap advancement.

- Anti-biotics.

- Discuss with patient.

- Record in case file.

- ENT consultation to assess the sinus health.

- Required radiographs and CT scans.

- Fix elective date for OAC closure.

- Routine work up/lab investigations.

- Decide on type of closure technique/anaesthesia.

- Decide whether there is need for Caldwell luc/ FESS/nasal antrostomy after sinus evaluation.

- Start antral regime.

- Start antral lavage until clear washout is achieved.

- Execute the surgery.

- Follow up to assess the status of closure.
Clinical Scenario 3 (Fig. 24.27a, b, c and d)

Another interesting clinical scenario, which I came across in a maxillofacial trauma case recently, is given as follows:

A 36-year-old male sustained RTA and facial fractures as seen in Fig. 24.27a and b. Tooth numbers 15 and 16 (upper right first pre-molar and molar) were avulsed with comminution of labial cortical plate and the alveolar process creating an oroantral communication (Fig. 24.27c). You can appreciate the bubbling of mucus at the OAC site. CT showed bilateral haemosinus, fracture maxilla and mandible, The right posterior alveolar segment containing 17,18 (upper right second molar and third molar) was mobile and extruded due to a posterior right parasagittal fracture of the maxilla.

It was a challenging case to plan and execute.

The upper sub-labial incision, given for the maxillary fracture exposure, was curved down distal to 14 (upper right first pre-molar) and continued as a full thickness crevicular mucoperiosteal flap. The distal release was not given, for fear of jeopardizing the vascularity of the posterior alveolar segment. The BFP was mobilized in the conventional way (Fig. 24.27d), and a good two-layered primary closure was attained after reduction and fixation of the fractures. The posterior alveolar segment had to be fixed to the main segment via transosseous wiring. This segment was extruded, and to achieve healing and occlusion, post-operative IMF was given. This particular patient was on Ryles Tube feeding for few days, mainly due to other injuries and tracheostomy, which would have helped in the good healing of the OAC closure.
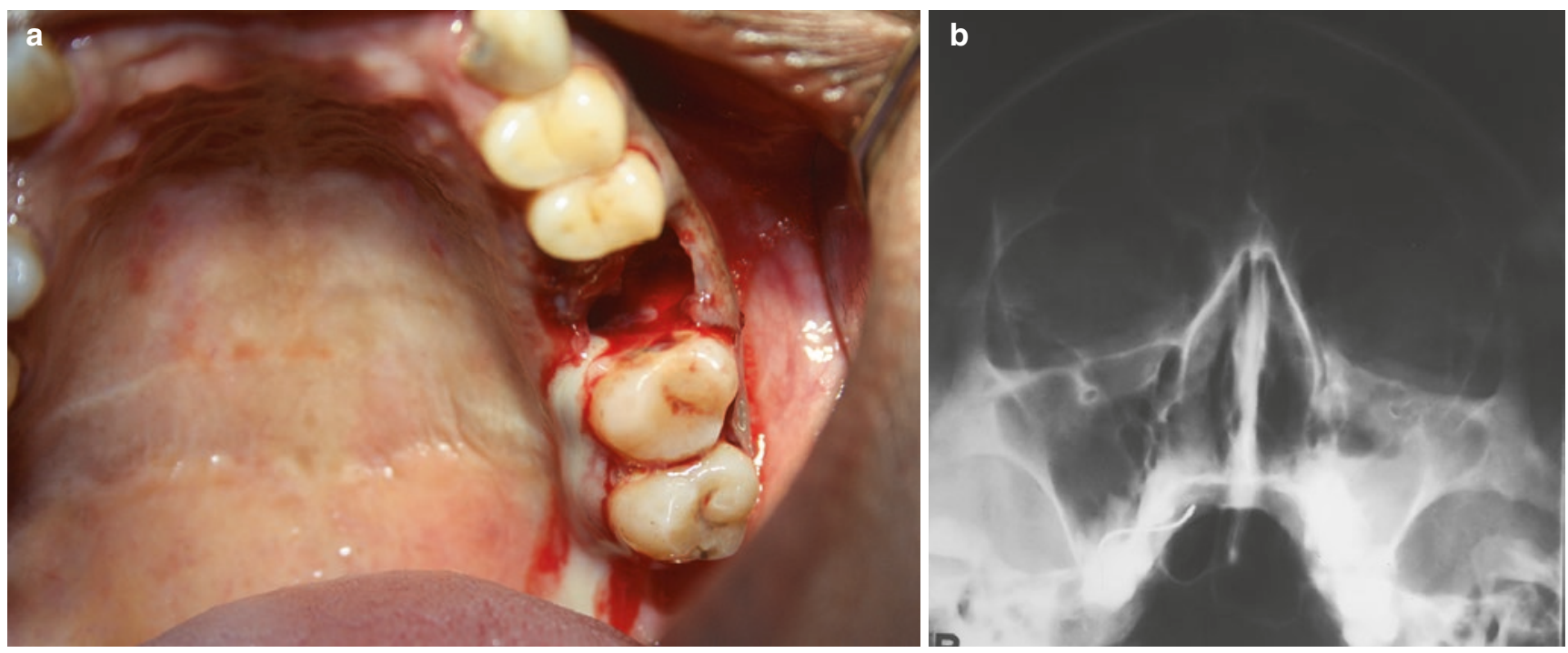

CAssociation of Oral and Maxillofacial Surgeons of India

Fig. 24.26 (a) Surprise finding of pus from socket after extraction of upper left first molar root stumps, (b) PNS view taken after extraction shows fluid level in the sinus, probably due to pre-existing sinusitis 

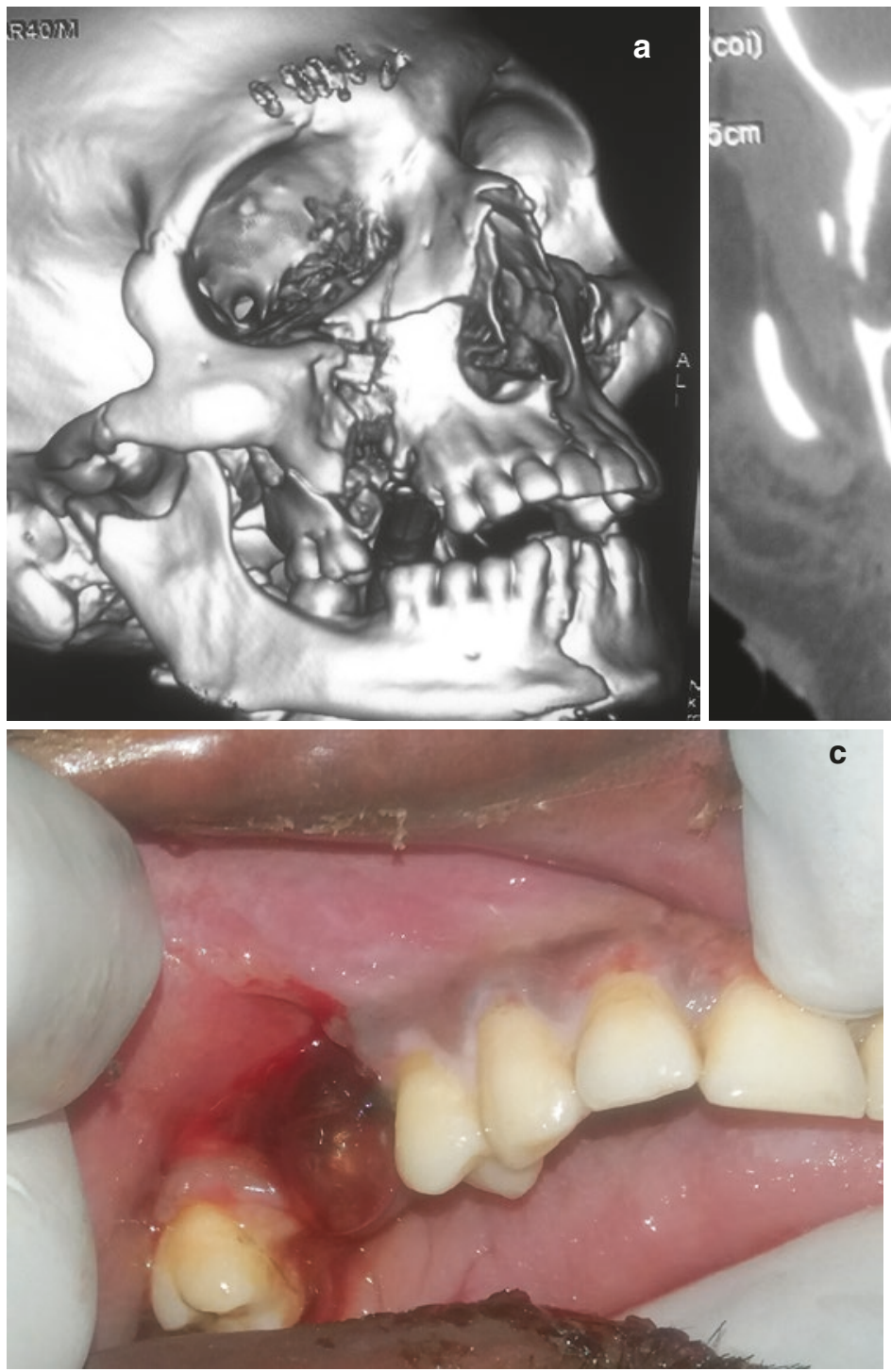

CAssociation of Oral and Maxillofacial Surgeons of India

C
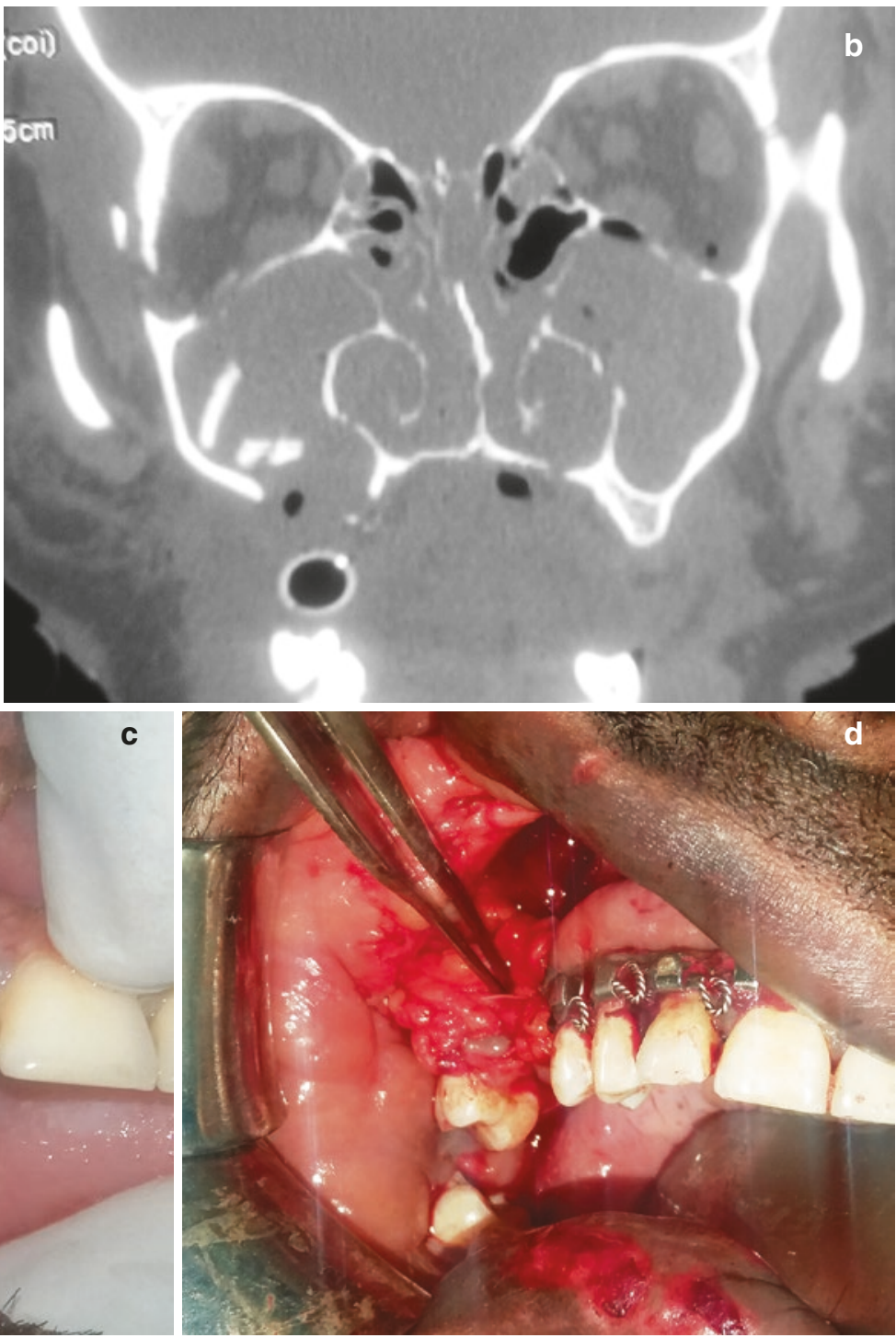

Fig. 24.27 (a, b, c and d) OAC following maxillofacial trauma (see the text for details)

\subsection{Conclusion}

The clinician should be cautious of not deliberately causing an OAC while performing exodontia and dentoalveolar procedures in maxillary posterior region. An OAC should be ruled out in suspected cases, and if it occurred, necessary steps should be taken to ensure a closure primarily if possible. Even as this chapter is going to the publishers, clinicians are exploring the possibilities of new techniques, of which the flapless closure techniques of acute OAC seem to be quite promising. Closing OAC with PRF membrane/collagen composite $[53,54]$ offers easier, less traumatic methods to close OAC, which may even obviate the need for special surgical expertise. Materials like acellular dermal/ bone matrix are also being used recently [55] However, only time will prove the obduracy of these path breaking methods.

Visscher [56] in a retrospective study of 308 oroantral closures found that about $10 \%$ needed re-operation, and patients with maxillary sinusitis had 15 times higher risk of developing a recurrence.

Dealing with OAF cases is interesting in the sense that it involves assessing the health of sinus and choosing and performing the most suitable surgical technique, most of which are fine surgeries. It is indeed rewarding to see a symptom-free patient with a well-healed OAF closure site. 


\section{References}

1. Eberhardt JA. A computed tomographic study of the distances between the maxillary sinus floor and the apices of the maxillary posterior teeth. Oral Surg Oral Med Oral Pathol. 1992;73(3):345-6.

2. von Wowern N. Correlation between the development of an oroantral fistula and the size of the corresponding bony defect. J Oral Surg. 1973;31:98.

3. Dym H. Oroantral communication. Oral Maxillofac Surg Clin N Am. 2012 May;24:239-47.

4. Visscher S, et al. Closure of oroantral communications: a review of the literature. JOMS. 2010;68:1384-91.

5. Awang MN. Closure of oroantral fistula. IJOMS. 1988;17:110-5.

6. Kitagawa Y. Use of third molar transplantation for closure of the oroantral communication after tooth extraction: a report of 2 cases. Oral Surg Oral Med Oral Pathol Oral Radiol Endod. 2003;95(4):409-15.

7. Procacci P. Surgical treatment of oroantral communications. J Craniofac Surg. 2016;27(5):1190-6.

8. Welty CF. Closure of fistulous opening through alveolar process in the antrum of Highmore. JAMA. 1920;75:867-9.

9. Moczair L. Nuovo methodo operatiopela chisura delle fistole del seno mascellase di origina dentale. Stomatol (Roma). 1930;28:1087-8.

10. Rehrmann VA. Eine methods zur Schliessung von Kiejerhohlen perforationen. Deutsche Zahnarztliche Wochenschrift. 1936;39:1136-9.

11. Berger A. Oroantral openings and their surgical corrections. Arch Otolaryngol. 1939;130:400-2.

12. Ashley RE. Method of closing antroalveolar fistula. Ann Otol Rhinol Laryngol. 1939;48:632.

13. Kruger GO. Text book of oral and maxillofacial surgery. 6th ed. St Louis: CV Mosby; 1984. p. 291-3.

14. Kazanjian VZ, Converse JM. The surgical treatment of facial injuries. Baltimore: Williams; 1949.

15. McClung EJ. Tantalum foil used in closing antro-oral fistulas. US Armed Forces Med J. 1951;7:1183.

16. Schuchardt K. Methodik des Verschlus-ses von Defekten im alveolarforsate zahn-lose oberkiefer. Dtsh Zahn Mund Kieferheilk. $1953 ; 17: 366-9$.

17. Guerrero-Santos J. The use of lingual flaps in repair of fistulas of the hard palate. Plast Reconstr Surg. 1966;38(2):123-8.

18. Rintala A. A double, overlapping hinge flap to close palatal fistula. Scand J Plast Reconstr Surg. 1971;5(2):91-5.

19. Ziemba RB. Combined buccal and reverse palatal flap for closure of oral-antral fistula. J Oral Surg. 1972;30(10):727-9.

20. Meyerhoff W. Gold foil closure of oroantral fistula. Laryngoscope. 1973;83:940.

21. Henderson D. The palatal island flap in the closure of oroantral fistulae. British JOS. 1974;12:141.

22. Choukas NC. Modified palatal flap technique for closure of oroantral fistulas. J Oral Surg. 1974;32(2):112-3.

23. Gullane PJ. Palatal island flap for reconstruction of oral defects. Arch Otolaryngol. 1977;103(10):598-9.

24. Cockerham S. Closure of a large oroantral communication by bone grafting. J Oral Surg. 1976;34(12):1098-100.

25. Egyedi P. The bucket-handle flap for closing fistulae around the premaxilla. J Maxillofac Surg. 1976;4(4):212-4.

26. Egyedi P. Utilization of the buccal fat pad for closure of oro-antral and/or oro-nasal communications. J Maxillofac Surg. 1977;5:241.

27. Sachs SA. Treatment of a persistent oro-antral fistula with a posteriorly based lateral tongue flap. Int J Oral Surg. 1979;8(3):225-8.

28. Ito T, Hara H. A new technique for closure of the oroantral fistula. J Oral Surg. 1980;38(7):509-12.

29. Quayle AA. A double flap technique for the closure of oro-nasal and oro-antral fistulae. Br J Oral Surg. 1981;19(2):132-7.
30. Brusati R. The use of an osteoperiosteal flap to close oroantral fistulas. J Oral Maxillofac Surg. 1982;40(4):250-1.

31. Al-Sibahi A. The use of soft polymethylmethacrylate in the closure of oro antral fistula. J Oral Maxillofac Surg. 1982;40:165-6.

32. Mitchell R. Immediate closure of oro-antral communications with a collagen implant. A preliminary report. Br Dent J. 1983;154(6):171-4.

33. Carstens MH. A new approach for repair of oro-antral-nasal fistulae. The anteriorly based buccinator myomucosal island flap. J Craniomaxillofac Surg. 1991;19(2):64-70.

34. Zide MF. Hydroxylapatite block closure of oroantral fistulas: report of cases. J Oral Maxillofac Surg. 1992;50(1):71-5.

35. Shaker MA. Competent closure of chronic oroantral fistula with Zenoderm. Egypt Dent J. 1995;41(3):1237-42.

36. Hanazawa Y. Closure of oroantral communications using a pedicled buccal fat pad graft. J Oral Maxillofac Surg. 1995;53(7):771-5.

37. Hori M. Application of the interseptal alveolotomy for closing the oroantral fistula. J Oral Maxillofac Surg. 1995;53(12):1392-6.

38. Salins PC, Kishore SK. Anteriorly based palatal flap for closure of large oroantral fistula. Oral Surg Oral Med Oral Pathol Oral Radiol Endod. 1996;82(3):253-6.

39. Pandolfi PJ. Three-layer closure of an oroantral-cutaneous defect. Int J Oral Maxillofac Surg. 2000;29(1):24-6.

40. Lee JJ. Repair of oroantral communications in the third molar region by random palatal flap. Int $\mathrm{J}$ Oral Maxillofac Surg. 2002;31(6):677-80.

41. Haas R. A preliminary study of monocortical bone grafts for oroantral fistula closure. Oral Surg Oral Med Oral Pathol Oral Radiol Endod. 2003;96(3):263-6.

42. Ogunsalu C. A new surgical management for oro-antral communication: the resorbable guided tissue regeneration membrane - bone substitute sandwich technique. West Indian Med J. 2005;54(4):261-3.

43. Steiner M. Metal plates and foils for closure of oroantral fistulae. JOMS. 2008;66:1551-5.

44. Visscher SH, van Minnen B, Bos RR. Closure of oroantral communications using biodegradable polyurethane foam: a feasibility study. J Oral Maxillofac Surg. 2010 Feb;68(2):281-6.

45. Sandhya G, et al. Surgical management of oro-antral communications using resorbable GTR membrane and FDMB sandwich technique: a clinical study. J Maxillofac Oral Surg. 2013;12(3):254-9.

46. Ram H. Use of auricular cartilage for closure of oroantral fistula: a prospective clinical study. J Maxillofac Oral Surg. 2016;15(3):293-9.

47. von Wowern N. Closure of oroantral fistula with buccal flap: Rehrmann versus Môczár. Int J Oral Surg. 1982;11(3):156-65.

48. Killey HC, Kay LW. An analysis of 250 cases of oro-antral fistula treated by the buccal flap operation. Oral Surg Oral Med Oral Pathol. 1967;24(6):726-39.

49. Bichat FMX. Anatomie generale: appliquee a la physiologie et la medecine, Paris; 1801. Cited in Stuzin JM, Wagstrom L, Kawamoto HK, Baker TJ, Wolfe A The anatomy and clinical applications of the buccal fat pad. Plast Reconstr Surg 1990;85:29.

50. Manuel S. Surej Kumar LK, Parvathi R Nair: the versatility in the use of Buccal fat pad in the closure of oro-antral fistulas. J Maxillofac Oral Surg. 2015;14(2):374-7.

51. Adams T. Repair of oroantral communications by use of a combined surgical approach: functional endoscopic surgery and buccal advancement flap/buccal fat pad graft. J Oral Maxillofac Surg. 2015;73(8):1452-6.

52. Huang YC. Caldwell-Luc operation without inferior meatal antrostomy: a retrospective study of 50 cases. J Oral Maxillofac Surg. 2012;70(9):2080-4.

53. Gülşen U. Etal. Flap-free treatment of an oroantral communication with platelet-rich fibrin. Br J Oral Maxillofac Surg. 2016;54(6):702-3. 
54. Pandikanda R, Singh R, Patil V, Sharma M, Shankar K. Flapless closure of oro-antral communication with PRF membrane and composite of PRF and collagen - a technical note. J Stomatol Oral Maxillofac Surg. 2018 Dec 29;120(5):471-3.

55. Li XY, Wu J, Cao J, Yang W, Wu B, Xie C.Clinical analysis of acellular dermal matrix and acellular bone matrix in oro-antral fistula repair. Hua Xi Kou Qiang Yi Xue Za Zhi 2018 Dec 1;36(6):633637. https://doi.org/10.7518/hxkq.2018.06.010. Chinese.

56. Visscher SH, van Roon MR, Sluiter WJ, van Minnen B, Bos RR. Retrospective study on the treatment outcome of surgical closure of oroantral communications. J Oral Maxillofac Surg. 2011 Dec;69(12):2956-61.

Open Access This chapter is licensed under the terms of the Creative Commons Attribution 4.0 International License (http://creativecommons. org/licenses/by/4.0/), which permits use, sharing, adaptation, distribution and reproduction in any medium or format, as long as you give appropriate credit to the original author(s) and the source, provide a link to the Creative Commons license and indicate if changes were made.

The images or other third party material in this chapter are included in the chapter's Creative Commons license, unless indicated otherwise in a credit line to the material. If material is not included in the chapter's Creative Commons license and your intended use is not permitted by statutory regulation or exceeds the permitted use, you will need to obtain permission directly from the copyright holder. 